\title{
The evolution of growth patterns in mammalian versus nonmammalian cynodonts
}

\author{
Rachel N. O'Meara and Robert J. Asher
}

\begin{abstract}
One of the major evolutionary transitions of the mammaliaform lineage was the origin of a typically mammalian pattern of growth. This is characterized by rapid juvenile growth followed by abrupt cessation of growth at adult size and may be linked with other important mammaliaform apomorphies of dental replacement and morphology. Investigation of growth patterns in the tritylodontid cynodont Oligokyphus and the basal mammaliaform Morganucodon provides insight into this crucial transition. We collected mandibular depth measurements from large samples of Morganucodon and Oligokyphus and constructed distributions of mandibular depth versus frequency for each species. These were compared with distributions from species from three different growth classes of extant amniote: testudines + crocodilians, mammals + birds, and lepidosaurs. Discriminant function analysis was used to differentiate between known growth classes by using different combinations of three measures of mandibular depth distribution shape (skew, kurtosis, and coefficient of variation) as proxies for different juvenile and adult growth patterns. Classification of the fossil species showed that Morganucodon closely resembled extant placental mammals in having rapid juvenile growth followed by truncated, determinate adult growth. Oligokyphus showed intermediate growth patterns, with more extended adult growth patterns than Morganucodon and slightly slower juvenile growth. This suggests a gradual evolution of mammalian growth patterns across the cynodont to mammaliaform transition, possibly with the origin of rapid juvenile growth preceding that of truncated, determinate adult growth. In turn, acquisition of both these aspects of mammalian growth was likely necessary for the evolution of diphyodont tooth replacement in the mammaliaform lineage.
\end{abstract}

Rachel N. O'Meara and Robert J. Asher. University Museum of Zoology, Downing Street, Cambridge, CB2 3EJ, United Kingdom. E-mail: rno21@cam.ac.uk

Accepted: 12 November 2015

Published online: 28 April 2016

Supplemental material deposited at Dryad: doi: 10.5061/dryad.8rv01

\section{Introduction}

Once erupted, teeth cannot increase in size (although some species, including rodents, have open-rooted dentitions and show continuous eruption). Therefore, continuous growth of the jaw requires that teeth are succeeded by larger replacement teeth or that additional teeth are added to the tooth row to maintain a functional dentition (Edmund 1960; Osborn 1974). Hence, in many amniotes with "indeterminate" growth patterns in which growth continues for most of the animal's life span (here referred to as "extended" adult growth) such as crocodilians, some dinosaurs, and some nonmammalian cynodonts, polyphyodont replacement of larger teeth has been linked with continuous jaw growth (Edmund 1960; Hopson 1971; Osborn 1971; Osborn and Crompton 1973; Westergaard and Ferguson 1986, 1987; Butler 1995). In contrast, determinate (or "truncated" in contrast to "extended") skull growth in mammals may limit the requirement for continuous tooth replacement (Crompton and Jenkins 1973; Zhang et al. 1998; Luo et al. 2004). This is supported by observations in mammals that most postnatal cranial growth (up to $80 \%$ ) occurs before deciduous eruption is complete (Crompton and Parker 1978) and that after the deciduous dentition has erupted relatively little further growth of the jaw is required to accommodate the replacement permanent dentition and new permanent molars (Pond 1977; Crompton and Parker 1978). Rapid juvenile growth, particularly of the skull, in mammals limits the time during which teeth of intermediate size are required and hence also permits the reduction of tooth replacement (Pond 1977; Zhang et al. 1998). Therefore, both determinate, truncated adult growth and rapid 
juvenile growth are correlated with, and may have permitted the evolution of, diphyodonty.

Maternal provisioning by lactation may also be linked with the evolution of diphyodonty (Ewer 1963; Hopson 1971, 1973; Zhang et al. 1998; Kielan-Jaworowska et al. 2004) since (1) maternal provisioning results in rapid juvenile growth, particularly of the skull relative to the postcranium (Pond 1977), and (2) functional teeth are not required until a neonate mammal is weaned, so eruption of the first generation of teeth is delayed in mammals relative to diapsids (Ewer 1963; Hopson 1971; Pond 1977). Thus, the jaw usually reaches a greater proportion of adult size at the time of eruption of the first generation of teeth in mammals compared with diapsids, further limiting the requirement for polyphyodonty in the former (Ewer 1963; Pond 1977). Variability may of course occur, but usually entails growth preceding eruption (Asher and Lehmann 2008; Asher and Olbricht 2009; Ciancio et al. 2012), rather than eruption preceding growth, for obvious mechanical requirements of having space in the jaw into which teeth may erupt (although in some species the relationship between size and eruption is not straightforward; cf. Godfrey et al. 2005). Lactation, diphyodonty, rapid juvenile growth, and determinate growth may in turn be linked with several other important mammalian morphological and behavioral apomorphies. These include increased precision of molar occlusion (Crompton and Jenkins 1973; Pond 1977; Crompton 1995); the increased complexity of enamel microstructure and evolution of enamel prisms, which may prevent propagation of cracks and hence reduce wear (Grine and Vrba 1980; Crompton et al. 1994); mammalian jaw-closing mechanisms (Crompton and Jenkins 1973; Pond 1977; Crompton and Parker 1978; Crompton 1995); and mutualistic social behavior (Pond 1977).

Dating from the Late Triassic-Early Jurassic, Morganucodon is the geologically oldest mammaliaform (defined following Rowe [1998] as the clade comprising the last common ancestor of Sinoconodon and crown Mammalia, and its descendants) and the most cladistically basal to have had diphyodont tooth replacement (Luo et al. 2002; Kielan-Jaworowska et al. 2004). Antemolars in Morganucodon were replaced only once, and molars were probably unreplaced in both M. watsoni and M. oehleri (Mills 1971; Parrington 1971, 1973, 1978; Kermack and Kermack 1984; Luo 1994; Crompton and Luo 1993), although further evidence is required to show that the ultimate molar was unreplaced (Luo et al. 2004). Similarly, molar replacement has not been observed in the morganucodontan Dinnetherium (Crompton and Luo 1993; Luo 1994), leading Luo et al. (2004) to suggest that mammal-like diphyodont tooth replacement may be common to all morganucodontans. The docodont Haldanodon is also diphyodont and lacks molar replacement (Martin and Nowotny 2000; Nowotny et al. 2001). The diphyodont condition is widely considered an apomorphy of the clade comprising the last common ancestor of morganucodontans and crown Mammalia and its descendants (Luo 1994; Kielan-Jaworowska et al. 2004; Luo et al. 2004), although some gobiconodontids do show replacement of at least anterior molariforms (Jenkins and Schaff 1988; Kielan-Jaworowska and Dashzeveg 1998), which may complicate this interpretation.

Given the theoretical links between diphyodonty and mammalian growth patterns, Luo et al. (2004) hypothesized that Morganucodon experienced determinate (truncated) growth and rapid juvenile growth and, by implication, may have provisioned its young by lactation. Evidence for determinate growth is based on the narrow range of skull lengths in M. oehleri (Luo et al. 2001, 2004; Kielan-Jaworowska et al. 2004). This range is much more restricted than that of the basal mammaliaform Sinoconodon, which did not have diphyodont tooth replacement (Zhang et al. 1998). Hence, M. oehleri was inferred to have had a more mammal-like growth pattern than Sinoconodon, and perhaps also nonmammalian cynodonts, although comparable studies have not been carried out in more basal cynodont species.

Rapid juvenile growth in Morganucodon has also been inferred from the high proportion of adult to juvenile specimens in $M$. watsoni (Parrington 1971, 1978; Kermack et al. 1973, 1981; Gow 1985; Luo 1994), suggesting that the juvenile stage was of short duration relative 
to overall life span in this genus (Gow 1985; Luo et al. 2004). In addition, bone histology supports the hypothesis of mammal-like growth patterns in Morganucodon; the high bone-deposition rates in early ontogeny, followed by a reduction in the rate of bone formation in M. watsoni, are similar to those observed in extant mammals (Chinsamy and Hurum 2006).

Here, we present evidence of determinate (truncated) growth and rapid juvenile growth in Morganucodon. Luo et al. (2001) suggested $M$. oehleri underwent determinate growth based on a necessarily limited sample of eight skulls (Luo et al. 2001, 2004). To further test this inference, we sample 531 dentaries of M. watsoni, a species (of the four currently recognized in Morganucodon) that has not previously been evaluated in this respect. By investigating a large sample of $M$. watsoni and comparing them with extant mammals and diapsids with known growth trajectories, we aim to establish the nature of growth in extinct taxa such as Morganucodon. Discriminant function analysis permits us to investigate both juvenile and determinate, truncated adult growth simultaneously and has the potential to illuminate not only whether or not growth was determinate or not but also the degree to which growth in Morganucodon resembles that of extant mammals.

Definitions of amniote growth patterns as either determinate or indeterminate can differ depending on the context of study (Lee et al. 2013). Life history studies usually define indeterminate growth as occurring if an animal continues to grow past sexual maturity (Charnov et al. 2001; Congdon et al. 2013), as in most nonavian diapsids. However, developmental or histological studies commonly adopt a definition of growth based on the plasticity of the growth trajectory of an individual as it ages (Lee et al. 2013). In this context, almost all amniotes exhibit lack of plasticity of growth in later life and thus have asymptotic and therefore determinate skeletal growth, contrasting with the truly indeterminate growth of plants (Sebens 1987). Thus, the term "indeterminate" is ambiguous when applied to amniotes. Hereafter we avoid this term, but distinguish between the relatively abruptly terminating growth of mammals and lepidosaurs as "determinate" or "truncated" adult growth and the less strongly plateaued growth of testudines and crocodilians (Fig. 1) as "extended adult growth."

Evidence from tooth replacement studies suggests that many nonmammalian cynodonts had "indeterminate" (extended) growth patterns (Kielan-Jaworowska et al. 2004; Luo et al. 2004). For example, in the epicynodont Thrinaxodon, small predecessor teeth are replaced by larger successors at posterior tooth loci even in large individuals, indicating that jaws continued to lengthen throughout life (Osborn and Crompton 1973). Bone microstructure studies show that there was considerable variation in growth strategies throughout the nonmammalian cynodont lineage (Botha and Chinsamy 2000, 2005; Ray et al. 2009; Botha-Brink et al. 2012), although with a general trend toward more rapid bonedeposition rate in more crownward groups (Ray et al. 2009; Botha-Brink et al. 2012). Several studies suggest that the growth strategy of nonmammalian cynodonts was more plastic than that of extant mammals, permitting decrease in growth rates in unfavorable conditions (Ray et al. 2004; Chinsamy and Hurum 2006; Chinsamy and Abdala 2008). Most cynodonts and therapsids show a decrease in growth rate in adulthood and eventual cessation of growth (Botha-Brink et al. 2012; Hurum and Chinsamy-Turan 2012). This clearly asymptotic growth pattern may be consistent with either mammal-like determinate, truncated growth or with relatively more extended growth patterns (although it is unlikely to resemble the more extreme extended adult growth of turtles and crocodilians).

The paucity of quantitative comparisons of absolute growth rates through ontogeny and the difficulties of accounting for the effect of differences in size on bone tissue growth (Botha-Brink et al. 2012), together with the flexible growth strategy of nonmammalian cynodonts, make it difficult to assess the degree to which growth trajectories differed between nonmammalian cynodonts and extant mammals. It is likely that growth patterns of many cynodonts were intermediate between 
those of a basal amniote ancestor with extended growth and those of extant mammals, although rapid growth with truncated adult growth has also been observed in some therapsids and basal cynodont species (Botha and Chinsamy 2005; Butler 2010; Huttenlocker and Botha-Brink 2014).

To probe this question of nonmammalian cynodont growth patterns, we also assessed size measurements from the tritylodontid Oligokyphus in this study and compared them with Morganucodon. Bone histology shows that tritylodontids exhibited sustained and rapid growth, which slowed later in ontogeny, similar to Morganucodon, suggesting they may also have had a fairly mammalian determinate, truncated pattern of adult growth (Chinsamy and Hurum 2006; Hurum and ChinsamyTuran 2012). Oligokyphus conforms to this tritylodontid pattern (de Ricqlès 1969), although with slower overall growth than in Tritylodon (Botha-Brink et al. 2012).

In addition, we assessed growth patterns in the extinct lepidosaur Gephyrosaurus bridensis. Gephyrosaurus is the most basal known rhynchocephalian (Evans and Jones 2010), and it likely had determinate, truncated adult growth and a slow period of juvenile growth, in common with extant lepidosaurs, including the only extant rhynchocephalian genus, Sphenodon. This is supported by its bone histology, which is similar to that of extant squamates (Chinsamy and Hurum 2006). Gephyrosaurus is particularly useful for our comparisons, because it occurs contemporaneously with Morganucodon watsoni (Evans 1980); specimens used in this study were from the same fissure-fill deposits (St. Bride's, Wales) as M. watsoni. This permits comparison of Morganucodon and Oligokyphus with another extinct taxon fossilized in a similar taphonomic environment and enables us to determine whether factors such as preservation bias affect the assignment of fossil species to a particular growth class in this study.

Morganucodon, Oligokyphus, and Gephyrosaurus specimens were compared with representatives from three different groups of amniotes that exhibit clearly distinct modes of growth (hereafter referred to as its growth class): (1) mammals + birds, (2) lepidosaurs, and (3) testudines + crocodilians.

\section{Extant Mammal + Bird Growth Class}

Mammals have a characteristic growth pattern in which juveniles grow rapidly to reach a maximum adult size, at which point growth abruptly ceases (determinate, truncated growth). This typically results in a sigmoid individual growth curve (Fig. 1) with a definite plateau (e.g., mice and rats [Eisen 1976]; Peromyscus maniculatus [Dice and Bradley 1942]; Sorex unguiculatus [Nesterenko and Ohdachi 2001]; domestic dog breeds [Helmink et al. 2000]; Monodelphis domestica [Cothran et al. 1985]; dolphins [Fernandez 1998]). The unique mammalian apomorphy of lactation permits rapid and sustained postnatal growth throughout juvenile and subadult stages. Growth is much faster in young mammals (Case 1978), which attain a much greater proportion of adult size and weight by the time of weaning relative to nonavian diapsids of comparable age and size (Pond 1977; Crompton and Parker 1978).

In particular, there is an accelerated rate of growth of the skull relative to the postcrania and of the facial region relative to the skull (e.g., Rattus norvegicus [Jackson and Lowrey 1912; Moss and Baer 1956]; Gorilla gorilla [Krogman 1931]; reviewed in Pond 1977). Among nonavian diapsids, skull and postcranial growth rates are roughly similar (e.g., Crocodylus niloticus [Cott 1961]). Lactation in mammals permits a delay in the eruption of the first generation of teeth relative to nonavian diapsids and, in many species, the rate of growth declines abruptly following weaning (Pond 1977). Therefore, in comparison with nonavian diapsids, relatively less growth occurs between complete eruption of the first generation of teeth and the attainment of maximum adult size (Pond 1977; Crompton and Parker 1978), permitting diphyodont tooth replacement, as discussed above. The cessation of growth is usually followed by the attainment of sexual maturity (Lee and Werning 2008), at least in mammals of small to medium size. In larger mammals with relatively prolonged periods of growth, such as elephants, sexual maturity is frequently attained before maximum adult size is reached, and growth curves, especially in male elephants, do not evince such distinct plateau regions as those of 
smaller mammals (Schrader et al. 2006; Lee and Werning 2008).

Extant birds have growth patterns similar to those of extant mammals, showing strongly plateaued growth curves and rapid juvenile growth (Case 1978; Lee and Werning 2008); they are therefore included within the same growth class, distinct from slow-growing nonavian diapsids. Precocial birds show growth rates similar to those of eutherian mammals of comparable size, while altricial birds grow at approximately twice the rate of comparable extant eutherians (Case 1978). Bone histology provides evidence for the evolution of this growth pattern within the dinosaurian lineage, suggesting that nonavian dinosaurs had elevated rates of growth in comparison with nondinosaurian diapsids (Erickson et al. 2001; Padian et al. 2001; Erickson 2005) but did not attain the extremely rapid growth rates of extant altricial birds (Erickson et al. 2001). Later, extreme reduction of the duration but not the rate of rapid juvenile growth may have enabled the miniaturization of neoavian birds (Padian et al. 2001; Lee and Werning 2008).

The mammal + bird growth class is therefore defined as having rapid juvenile growth and determinate, truncated adult growth.

Nonavian diapsids differ from mammals in having growth rates an order of magnitude lower than mammals of comparable weight (Case 1978). Even in elephants, which have relatively slow growth and a more prolonged period of growth than other mammals, growth rates are far in excess of even the fastestgrowing large extant nonavian diapsids (Case 1978). Growth in nonavian diapsids also differs from mammals in that it can be arrested or greatly reduced during unfavorable environmental conditions and increased again when conditions improve (Pond 1977; Adolph and Porter 1996). Furthermore, in contrast to most mammals, significant growth continues after sexual maturity in nonavian diapsids (Andrews 1982; Shine and Charnov 1992; Shine and Iverson 1995; Scheyer et al. 2010), including in some nonavian dinosaurs (Sander and Klein 2005). Nonavian diapsid growth trajectories may be divided into two distinct types: determinate, truncated growth in lepidosaurs and extended growth in testudines and crocodilians.

\section{Lepidosaur Growth Class}

Determinate, truncated growth, in which a maximum adult size is reached and growth then terminates relatively abruptly, is observed in most extant lepidosaurs (Shine and Charnov 1992). Their growth curves show a distinct plateau when maximum size is reached (e.g., van Devender 1978; Kolarov et al. 2010; Zúñiga-Vega et al. 2005). Bone histology studies in squamates show that there is a decrease in the rate of bone deposition with increasing age and that bone deposition ceases many years before death, as in mammals (Castanet and Báez 1991; Chinsamy et al. 1995). This is true also in the only living species of rhynchocephalian, Sphenodon punctatus, which has slower growth than any other living reptile (Castanet et al. 1988). In this species, size reaches a maximum at between 20 and 35 years of age; an individual may continue living without further growth for more than 30 years (Dawbin 1982). Complete fusion of long-bone epiphyses occurs in a taxonomically broad range of squamates (Haines 1969; Maisano 2002). Maisano (2002) found that this indicates that an individual is within $20 \%$ of the species maximum size (although the individual may have reached its own maximum), consistent with determinate, truncated skeletal growth in this group.

We thus define the lepidosaur growth class as having slower juvenile growth and determinate, truncated adult growth.

\section{Testudine + Crocodilian Growth Class}

Growth in testudines and crocodilians commonly continues throughout life, with the qualification that growth rates slow with age (Porter 1972; de Ricqlès 1976; Andrews 1982; Scheyer et al. 2010). Most studies on testudine growth patterns focus on growth after sexual maturity (a definition of "indeterminate" growth that we try to avoid in this study), rather than on lifetime growth, and show that such continued growth after maturity is common in a range of taxa (Dunham and Gibbons 
1990; Lovich et al. 1990; Congdon et al. 2003), although again growth slows with age to become almost negligible in later life (Balazs 1980; Frazer and Ladner 1986; Zug et al. 1986; Seminoff et al. 2002; Bjorndal et al. 2013). The attainment of skeletal maturity (Woodward et al. 2011) and cessation of growth is certainly possible (Wilkinson and Rhodes 1997) in some crocodilians and is quite probably more widespread in the group than previously thought. Whether cessation of growth is common among testudines and crocodilians is difficult to establish due to variation of individual growth patterns within a species (Carr and Goodman 1970; Tucker et al. 2006; Congdon et al. 2013) and the paucity of long-term studies focusing on lifetime growth rather than growth following sexual maturity.

However, some studies have also investigated growth in individual testudines across the lifetime size range of a species and found that some growth, albeit slow, continues even in the largest turtles (Zug et al. 1986; Seminoff et al. 2002). Gradually declining growth of this kind has also been observed in crocodilians, with growth rates slowing, and in some individuals ceasing, in later life (Cott 1961; Andrews 1982; Rootes et al. 1991; Wilkinson and Rhodes 1997; Tucker et al. 2006). Thus, the relatively abrupt decline in growth rates typical of determinately growing lepidosaurs is not apparent in testudines and crocodilians. Andrews (1982) reports that the inflection points of growth curves of iguanids (lepidosaurs) tend to occur at lengths greater than $50 \%$ of asymptotic (maximal) length and mass. In large, longer-lived reptiles, such as crocodilians, inflection points are closer to 30\% of asymptotic (maximal) mass, indicating a less distinct plateau in growth curves of the crocodilians. Lack of complete epiphyseal ossification in testudine and crocodilian long bones suggests that continued growth throughout life is physiologically possible in these animals (Haines 1969). Lack of epiphyseal ossification in very large individuals is also seen in some large, longlived lepidosaur species, such as varanids (de Buffrénil et al. 2004). There is therefore some overlap in growth patterns between testudines + crocodilians and lepidosaurs. In this study, we included only smaller lepidosaur species in our sample, as our focus is on comparably small mammals, but future studies might profitably examine this overlap by inclusion of additional species of large nonavian diapsids.

Since most testudines and crocodilians show growth throughout the majority of their life span and lack the relatively more abrupt termination of growth characteristic of determinately growing lepidosaurs, their mode of growth can be considered to be distinct. We refer to this pattern of continuous, gradually declining lifetime growth in testudines and crocodilians as "extended growth." Testudines and crocodilians also show the slower juvenile growth typical of extant diapsids, as outlined above.

Thus, we divide extant amniotes into three growth classes: (1) mammals + birds with rapid juvenile growth followed by determinate, truncated growth; (2) lepidosaurs with slow juvenile growth followed by determinate, truncated growth; and (3) testudines + crocodilians with slow juvenile growth followed by extended adult growth. We used linear size measurements (mandibular depth) taken from different species belonging to each of these growth classes to construct a size-frequency distribution for each species. We aimed to establish whether a species could be assigned to its correct growth class on the basis of metrics relating to the shape of these size distributions, using discriminant function analysis. The three species of unknown growth class-Morganucodon, Oligokyphus, and Gephyrosaurus - were then classified on the basis of the resulting statistical model. This permitted growth patterns in Morganucodon and Oligokyphus to be compared with each other and with those of extant amniotes of known growth patterns, to better illuminate the evolution of mammalian growth patterns across the nonmammaliaform cynodont to mammaliaform transition.

\section{Materials and Methods}

\section{Museum Abbreviations}

FMNH, Field Museum of Natural History, Chicago, U.S.A.; NEWHM, Hancock Museum, Newcastle, U.K.; NHMUK, Natural History Museum, London, U.K.; OUM, Oxford University Museum of Natural History, Oxford, 


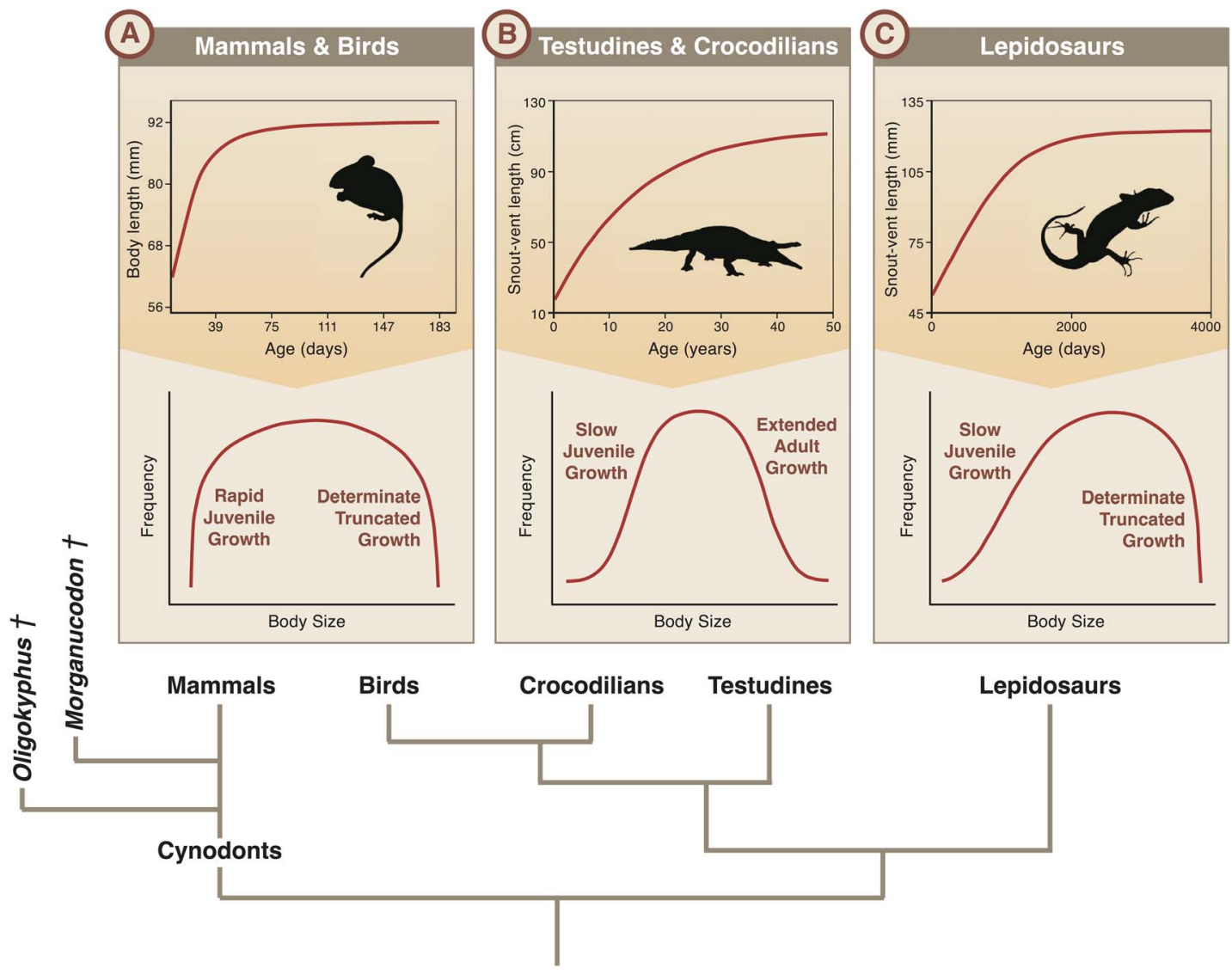

FIGURE 1. Individual growth curves (top) and expected differences in size-frequency distributions (middle) of different growth classes with a phylogeny of extant amniotes (bottom). A, Mammals and birds have rapid juvenile growth followed by determinate, truncated adult growth. Thus, both tails of the distribution are expected to be relatively truncated, and the mammal + bird distribution is expected to show more negative kurtosis and lower coefficient of variation $(\mathrm{CV})$ than the other groups. $\mathrm{B}$, Testudines and crocodilians have slow juvenile growth followed by extended adult growth. Thus, both tails of the distribution are expected to be relatively long in comparison with the mammal + bird distribution. The testudine + crocodilian distribution is expected to be less negatively skewed than that of lepidosaurs and with less negative kurtosis and greater $C V$ than either of the other groups. C, Lepidosaurs have slow juvenile growth followed by determinate adult growth. Thus, the right tail is expected to be relatively truncated, but the left tail is expected to be relatively long compared with mammal + bird distributions. The lepidosaur distribution is expected to be more negatively skewed than the other distributions, with an intermediate $C V$. Individual growth curves after: Peromyscus maniculatus: Dice and Bradley (1942); Crocodylus johnstoni: Tucker et al. (2006); Xenosaurus grandis: Zúñiga-Vega et al. (2005). Phylogeny of extant amniotes follows phylogenomic analyses by Chiari et al. (2012) and Crawford et al. (2015), with fossil cynodont relationships following Luo et al. (2002).

U.K.; UCL, University College London, U.K.; UCLGMZ, University College London, Grant Museum of Zoology, London, U.K.; UMZC, University Museum of Zoology, Cambridge, U.K.

Assigning Growth Classes to Morganucodon and Oligokyphus using Distribution Shape of Size Data

We collected mandibular depth measurements from Morganucodon, Oligokyphus, and
Gephyrosaurus specimens and compared these with large sample sizes of similar measurements from different extant amniotes belonging to the three major growth classes. In species with determinate, truncated growth (mammals + birds and lepidosaurs; Fig. 1A,C) one would expect the right tail of a size-frequency histogram of mandibular depth measurements to be relatively more truncated than the right tail of such a distribution from a testudine or crocodilian with extended adult growth (Fig. 1B). 
This results from the fact that a few very old individuals would reach extreme size in testudines and crocodilians. In contrast, in the determinately growing species even the oldest individuals would have ceased growing at a predetermined maximum size. In species with rapid juvenile growth (mammals + birds), one would expect the left tail of the distribution to be relatively more truncated (Fig. 1A) than in those species with slower juvenile growth (testudine + crocodilian and lepidosaur growth class; Fig. 1B,C). This is because individuals with rapid juvenile growth spend a relatively shorter proportion of their life spans at a small size. Thus, fewer small individuals are expected to be present in a given population at any one time relative to species with slower juvenile growth. Differences in the shapes of the sizefrequency distributions would therefore allow more nuanced quantification of the idea that high ratios of adult to juvenile specimens indicate rapid juvenile growth (Parrington 1971, 1978; Kermack et al. 1973, 1981) or that a narrow range of specimen sizes indicates determinate, truncated growth in Morganucodon (Luo et al. 2001, 2004).

Distribution shape can be quantified and compared using three different measures: skewness, kurtosis, and the coefficient of variation $(C V)$. Skewness is a measure of the asymmetry of a distribution, while kurtosis is a measure of the relative proportions of data found in the shoulders versus tails of a distribution. A negatively kurtotic distribution has a greater proportion of data in the shoulders than the tails relative to a normal distribution, while a positively kurtotic distribution has more data in the tails or center of the distribution and less data in the shoulders (Sokal and Rohlf 2012). Figure 1 illustrates expected differences between the sizefrequency distributions of different growth classes. With relatively truncated left tails (individuals pass through small size quickly) and right tails (individuals stop growing abruptly), one would expect a distribution from a species of the mammal + bird growth class to be relatively more negatively kurtotic than the distribution from a testudine + crocodilian or lepidosaur growth class. With a truncated right tail but a longer left tail, one would expect a lepidosaur distribution to be relatively more negatively skewed than distributions from testudine + crocodilian or mammal + bird growth classes. One would expect a testudine + crocodilian distribution to be less negatively kurtotic than a mammal + bird distribution, less negatively skewed than a lepidosaur distribution, and probably also less negatively skewed than a mammal + bird distribution, as the right tail would be longer than in either of the other groups.

The $C V$ is a normalized measure of dispersion of data and is the standard deviation divided by the mean, which may be expressed as a percentage (Sokal and Rohlf 2012). This permits comparison of the variation of size data of different species, taking into account differences in means. One would expect lowest $\mathrm{CV}$ values of body-size indices in members of the mammal + bird growth class, as both tails of their size-frequency distributions would be relatively short (rapid juvenile growth, determinate, truncated adult growth). Intermediate $\mathrm{CV}$ values would be expected in species of the lepidosaur growth class, as only one tail is expected to be relatively truncated (slow juvenile growth, determinate, truncated adult growth). The greatest $C V$ values would be expected in the testudine + crocodilian growth class, in which both tails would be relatively long (slow juvenile growth, extended adult growth).

\section{Specimens}

We measured 531 specimens of Morganucodon watsoni held at the UMZC and 49 specimens of Oligokyphus sp. from the NEWHM, NHMUK, and UMZC. The M. watsoni specimens were from the Pont Alun quarry, Glamorgan, South Wales, and were previously designated as the species Eozostrodon parvus. The Welsh form of E. parvus is now considered to be indistinguishable from $M$. watsoni, although E. parous is still a valid taxon for specimens from Holwell quarry, Oxfordshire (Clemens 1979). The fissure-fill deposits at the Pont Alun quarry are part of the St. Bride's Island locality, Wales, and were formed in Carboniferous limestone (Robinson 1957). The St. Bride's fissures are between the latest 
Triassic (Rhaetian) and the Early Jurassic (Sinemurian) in age (Kermack et al. 1973; Kielan-Jaworowska et al. 2004; Säilä 2005), although they are generally agreed to be Early Jurassic, most probably Sinemurian (Robinson 1957; Kermack et al. 1981; Evans and Kermack 1994). Gephyrosaurus bridensis specimens were from the same locality as $M$. watsoni and come from collections at UCL and UMZC.

All Oligokyphus specimens were from the Mendip 14 locality, Windsor Hill, Shepton Mallet, England. This locality is also a fissurefill deposit formed in Carboniferous limestone but is Charmouthian (Pliensbachian) and thus younger than the St. Bride's fissures (Kühne 1956). The Mendip adult Oligokyphus specimens comprise two size morphs (Kühne 1956), and Oligokyphus mandibular depth distribution from this study shows significant departure from unimodality (Supplementary Material S8). Although Kühne (1956) named the small and large forms as separate species (Oligokyphus minor and Oligokyphus major, respectively), he also considered it likely that the two morphs may result from sexual dimorphism within one species, especially as there are few morphological differences between the two forms. Since juvenile specimens had to be included in this study, and due to the difficulty of distinguishing O. major from $O$. minor based only on dentary fragments, we treated the two morphs as a single species, here referred to simply as Oligokyphus sp. Of course, if the two morphs are in fact distinct species, conclusions regarding their growth cannot be drawn from this analysis, and so results from Oligokyphus must be interpreted with this in mind.

We also measured extant amniotes representative of the three different modes of growth, including 13 species across 8 orders and 13 families of extant mammals, and 5 species across 5 families of birds. Mammals included bats (Pipistrellus kuhli), marsupials (Didelphis marsupialis, Dasyurus hallucatus), xenarthrans (Dasypus novemcinctus), rodents (Microtus agrestis, Tatera indica, Mus musculus), lipotyphlans (Sorex araneus, Talpa europaea, Suncus murinus, Erinaceus europaeus), and carnivorans (Mustela erminea and Canis familiaris). Bird species included falcons (Falco tinnunculus), finches (Fringilla montifringilla), pigeons (Columba livia), rails (Gallinula chloropus), and kingfishers (Alcedo atthis). Minimum sample size for any individual species was 40 . Mammal and bird specimens are held at the NHMUK and UMZC. Numbers of monotreme specimens available in museum collections are limited, and hence no monotreme is included in our mammal sample. Thus, our "mammal" growth class is based on Theria, excluding monotremes and other, nontherian crown mammals.

Museum collections of more than a handful of individual testudines or crocodilians of the same species are rare, but we did find samples $>40$ for 4 species of extant testudines and crocodilians (spanning 4 distinct families) at the collections of the FMNH, NHMUK, OUM, and UMZC. These included sea turtles (Chelonia mydas), tortoises (Testudo graeca), terrapins (Mauremys caspica), and caimans (Caiman crocodilus). Thirteen extant species across 10 lepidosaur families were included from the $F M N H$, NHMUK, OUM, UCL, UCLGMZ, and UMZC: lacertids (Lacerta viridis, Podarcis muralis, Acanthodactylus boskianus), skinks (Mabuya striata), geckos (Tarentola gigas, Tarentola annularis, Bunopus tuberculatus), snakes (Lapemis curtus, Typhlops schlegeli, Natrix maura), agamids (Agama sinaita, Calotes versicolor), and anguids (Anguis fragilis). The minimum sample size for any individual lepidosaur species was 63 .

Within each species, we took measurements from all specimens available in the museum collections with the relevant anatomy preserved. The only specimens excluded for reasons other than damage were those that had been collected with an explicit age-related bias. For example, a box containing only juvenile specimens, within an otherwise unsorted collection of specimens, was excluded. We assume that the proportions of differently sized museum specimens reflect those of animals in the original populations or at least that any bias in collecting from a particular size group applies consistently across growth classes. Here we follow previous studies (e.g., Parrington 1971; Gow 1985; Luo et al. 2001, 2004; Kielan-Jaworowska et al., 2004) that have commonly inferred growth patterns in mammaliaforms using the relative 
proportions of small to large individuals or the size ranges of sampled species; our method is simply an extension of these types of studies. Moreover, our access to mammaliaforms (Morganucodon) and lepidosaurs (Gephyrosaurus) from the same basal Jurassic localities in South Wales provides a further means to test whether differences we observe between them are due to artifacts of taphonomy or actual patterns of growth. Ideally, time-homogenous sampling of a species, from birth to death, would be used to test this assumption. Unfortunately museum samples generally do not have data on individual ages, and no sample can guarantee even representation across age cohorts of populations that have been extinct for millions of years. However, to the extent that such data could be collected for extant species (difficult but not impossible for long-lived species such as sea turtles) they would certainly comprise a valuable, future test of our conclusions.

\section{Measurements}

We measured dentary depth as a proxy for overall size in Morganucodon, Oligokyphus, and all mammal species using fossil or osteological specimens, as it is among the most consistently preserved metric we could recognize across fossil and extant members of our sample. We defined dentary depth as the shortest distance from the base of the anterior border of the coronoid process to the ventral edge of the dentary, in lateral view (Fig. 2).

Measurements closely analogous to dentary depth at the anterior coronoid process were taken from the lepidosaur, testudine, and crocodilian specimens. For most of these diapsid species, osteological specimens were used. In those species in which sutures were clearly visible, we defined mandibular depth as the shortest distance from the anterior edge of the coronoid bone to the ventral edge of the mandible, in lateral view. Where this was not possible, we measured mandibular depth from the posterior edge of the tooth row to the ventral edge of the mandible. In diapsid wet specimens or (in the case of bird specimens) skins, we defined mandibular depth as the shortest distance from the posterior-most extent of the oral cavity to the ventral edge of

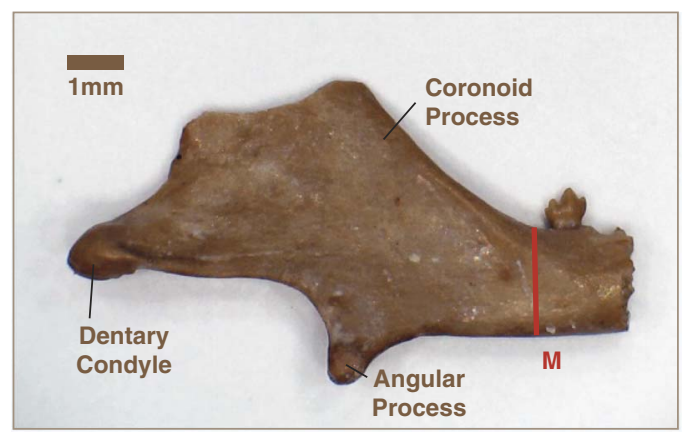

FIGURE 2. Mandibular depth measurement in the Morganucodon specimen (UMZC D61). Mandibular depth (M) in extant mammals, Morganucodon, and Oligokyphus was defined as the shortest distance from the base of the anterior border of the coronoid process to the ventral edge of the dentary, in lateral view.

the mandible in lateral view. Any loose tissue around the area being measured was pulled as taut as possible to standardize measurements. Within a species, the same definition of mandibular depth was used for all individuals. This enabled assessment of how mandibular depth is distributed at varying growth stages within a species and did not require identification of homologous landmarks between species.

The majority of species chosen were of small size, so as to be comparable to Morganucodon. For these species, we took measurements to the nearest $0.1 \mathrm{~mm}$ using a light microscope and graticule. For larger species, measurements were taken to the nearest $0.1 \mathrm{~mm}$ using digital calipers. When digital calipers were used, we took an average of three measurements of mandibular depth for each individual.

\section{Statistics}

Distributions of mandibular depth for each species can be quantified using different measures of the shape of the size-frequency distribution. In this study, we used three such measures for mandibular data of each species: Fisher's skewness, Fisher's kurtosis, and the $C V$. Skew, kurtosis, and CV of each species' data distribution, and also Box-Cox power transformation of variables in order to meet assumptions of discriminant function analysis (Supplementary Material S2.2), were calculated 
in the statistical program R, Version 2.15.1 ( $R$ Core Team 2012). Whenever multiple significance tests were carried out, false discovery rate (FDR) corrections (Benjamini and Hochberg 1995; Curran-Everett 2000) were applied to $p$-values.

Discriminant Analysis of Distribution Shape.Stepwise discriminant analysis was carried out, including all species listed above, using the statistical program SPSS, Version 21, to assess whether the three measures of mandibular depth distribution shape (skew, kurtosis, and $\mathrm{CV}$ ) can be used to assign a particular species to one of the three growth classes: mammal + bird, testudine + crocodilian, or lepidosaur. Discriminant analysis is a multivariate statistical technique in which predictor variables (i.e., measures of distribution shape) are used to predict group membership (i.e., growth class) by finding dimensions along which known members of groups differ and deriving classification functions to predict group membership where it is unknown (i.e., for the fossil species Morganucodon, Oligokyphus, and Gephyrosaurus). The predictors most important in discriminating different groups were identified by the procedure in which predictor variables were added stepwise to the model, with all variables evaluated at each step to determine which contributed most to discrimination between groups by minimizing overall Wilks's lambda. The stepping-method criteria for predictor variable inclusion were twofold: maximum significance of $F$ to enter $=0.05$ and minimum significance of $F$ to remove $=0.1$. Interpretation of the structure matrix of correlations between predictors and discriminant functions permitted more detailed evaluation of how predictors discriminate groups. Only those correlations greater than $0.32(10 \%$ of the variance) were considered eligible for interpretation (Comrey and Lee 1992). Classification functions for predicting membership of the fossil species were derived, and cross-validation was used to assess the adequacy of these classification functions.

An additional analysis was carried out, similar to the main analysis described above, but excluding two mammal species, Canis familiaris and Dasyurus hallucatus, and two bird species, Fringilla montifringilla and Columba livia.
In Dasyurus and Fringilla, sample size barely reached the recommended minimum sample size for a robust test of skewness or kurtosis $(n=40)$. In Canis, although the majority of individuals were of the same breed (39 of 57 individuals were greyhounds), the remaining specimens were of unknown breed, albeit with similar cranial morphology to the greyhounds. However, the high variability in size and morphology of dog skulls could lead to misleading values of skew, kurtosis, and $C V$ in this species. We also analyzed only those Canis specimens unambiguously identifiable as greyhounds in a further analysis. Domestication of pigeons may have led to a similar problem in Columba livia. Canis, Dasyurus, Fringilla, and Columba were therefore excluded to test whether their inclusion biased results. The analysis was also repeated excluding the two marsupials, Didelphis and Dasyurus, to test whether the differing growth patterns of marsupials relative to placentals (TyndaleBiscoe 2001; Geiger et al. 2014) affect the position of fossil species relative to the mammals during classification.

Since the taxa in this study are not independent from one another, but related in a hierarchical phylogeny (Fig. 1), closely related species may resemble each other more than species selected at random, and hence phylogenetic signal is likely to be present in the data (Harvey and Pagel 1991; Münkemüller et al. 2012). This can introduce difficulties in interpreting discriminant function analyses, as correlation between the predictor variables (skew, kurtosis, $\mathrm{CV}$ ) and growth classes may be caused by both having phylogenetic signal. In an extreme case, even if a predictor variable had no relationship to growth class, members of a particular class may share similar predictor values simply because they are closely related. Thus, although presence of an underlying phylogenetic signal does not exclude the possibility of functional or growth effects (as such effects themselves are likely to have been influenced by phylogeny), phylogenetic and functional signals may be difficult to distinguish. In these circumstances, cases of convergent evolution can be extremely important in distinguishing phylogenetic from functional effects (Barr and Scott 2014; Chen and Wilson 2015). We have therefore included in our 
sample birds, which are known to have evolved their growth patterns independently from those of mammals (Fig. 1; Chiari et al. 2012; Crawford et al. 2015). The position of birds in the canonical discriminant function plot helps to determine the relative influences of functional (growth) versus phylogenetic effects. As birds and mammals are known to share a pattern of growth but are not each other's closest relatives, we can assume that mammal and bird species cluster together in this analysis because of common functionality and not solely because of their phylogenetic history.

Assessing the Effects of Body Size and Life History.-Following the discriminant analysis of mandibular depth distribution shape and classification of unknown species, an additional stepwise discriminant analysis was performed to assess the effects of body size and life history. This analysis included three additional predictor variables: mean mandibular depth (a proxy for overall size), maximum longevity, and mean number of offspring per year. It is probable that the shapes of distributions for individual species are influenced not only by patterns of growth but also by size and life history characteristics. For example, animals with larger body sizes tend to have relatively longer periods of juvenile growth than smaller animals (Lee and Werning 2008; Schrader et al. 2006), resulting in differences in a distribution of mandibular depths during ontogeny simply due to overall body size. Similarly, a species that produces many offspring per year may have a longer left tail (although such an effect would be further influenced by other factors such as juvenile mortality), and longevity may be expected to influence the length of the right tail. It is important that the members of different growth classes used in this study have a relatively even distribution of size and different life history strategies, otherwise it would be difficult to determine whether consistent differences in skew, kurtosis, or $C V$ are due to the differences in growth pattern or to consistent differences in size or life history variables between groups.

It is beyond the scope of this study to model the effects of all aspects of life history, but mean number of offspring per year and maximum longevity were included to at least partially test whether differences in life history confound the discrimination of groups. Life history data were obtained from peer-reviewed literature or from the Animal Ageing and Longevity Database (de Magalhaes and Costa 2009; Supplementary Material S5).

\section{Results}

The distribution of mandibular depths for each species shows a general pattern in the degree of skew and kurtosis observed, corresponding with the growth class to which it belongs. Table 1 gives mean values for skew, kurtosis, and $C V$ in each growth class, with values for individual species in the Supplementary Material (S1). Mean skew is close to zero among mammals + birds, which is also the growth class with the lowest mean $\mathrm{CV}$ and the only growth class for which mean kurtosis is negative. This is consistent with patterns of rapid juvenile growth and determinate adult growth in mammals and birds (Fig. 1), in which both tails of the mandibular depth distribution are relatively truncated. The testudines + crocodilians show the most positive mean kurtosis and the greatest mean $C V$ of the three growth classes, while mean skew is close to zero. These patterns of skew and kurtosis are consistent with slow juvenile growth and extended adult growth patterns (Fig. 1), in which neither tail of testudine + crocodilian data distributions is relatively truncated. Lepidosaurs show a mean kurtosis close to zero and have the most negative mean skew of the three growth classes. This is consistent with slow juvenile growth and determinate adult growth, in which only the right tails of the lepidosaur data distributions are relatively truncated (Fig. 1).

Thus, general patterns of data distribution conform to expectations for each growth class: unskewed but negatively kurtotic distributions for mammals + birds, negatively skewed distributions with no strong kurtosis for lepidosaurs, and unskewed distributions with large $C V$ s for testudines + crocodilians (Fig. 1).

\section{Discriminant Analysis of Distribution Shape}

Differences between growth classes were assessed by stepwise discriminant analysis using three predictor variables to assign membership to three groups. The three predictors were 
TABLE 1. Means and standard deviations of original and transformed predictor variables (skew, kurtosis, and CV) for each growth class.

\begin{tabular}{llcccc}
\hline \hline Growth class & $\begin{array}{l}\text { Predictor } \\
\text { variable }\end{array}$ & $\begin{array}{c}\text { Mean of original } \\
\text { variables }\end{array}$ & $\begin{array}{c}\text { SD of original } \\
\text { variables }\end{array}$ & $\begin{array}{c}\text { Mean of transformed } \\
\text { variables }\end{array}$ & $\begin{array}{c}\text { SD of transformed } \\
\text { variables }\end{array}$ \\
\hline Mammals + birds & Skew & -0.10 & 0.15 & 2.0981 & 0.172 \\
& Kurtosis & -0.97 & 0.33 & 0.6245 & 0.155 \\
Testudines + & CV & 12.42 & 5.36 & 1.0093 & 0.002 \\
crocodilians & Skew & 0.06 & 0.36 & 2.2772 & 0.408 \\
Lepidosaurs & KV & 0.80 & 1.49 & 0.2692 & 0.097 \\
& Skew & 33.86 & 15.53 & 1.0132 & 0.002 \\
& Kurtosis & -0.49 & 0.23 & 1.6552 & 0.259 \\
& CV & 0.04 & 0.91 & 0.3540 & 0.099 \\
\hline
\end{tabular}

variables relating to the shape of the sizefrequency distribution of each species: the skew, the kurtosis, and the $C V$.

Following Box-Cox power transformations of variables (Sokal and Rohlf 2012; see Supplementary Material S2) significant heterogeneity of variance-covariance matrices was found (Box's $M$ test, $p<0.05)$. Heterogeneity of variance-covariance matrices (which measures multivariate dispersion) may not cause problems with inference but can do so for classification (Tabachnick and Fidell 2007). Therefore, we performed classification based on separate covariance matrices for each group, rather than the pooled within-group variance-covariance matrix, as recommended by Tabachnick and Fidell (2007). This procedure may lead to overfitting, in which classification functions, as estimates of group membership, work well for the sample from which they were derived but do not generalize across the whole population. Therefore, cross-validation was also carried out to test how well classification functions derived from only a subset of the data could classify withheld data.

Stepwise discriminant analysis extracted two discriminant functions (Table 2B; combined Wilks's lambda $=0.111, \chi_{(6)}^{2}=68.3$, $p<0.001)$. There remains a significant association between groups and predictors after removal of the first function (Table 2B; Wilks's lambda $\left.=0.365, \chi_{(2)}^{2}=31.2, p<0.001\right)$, indicating that both functions may be considered reliable discriminants of the groups. The first and second discriminant functions account for $57.0 \%$ and $43.0 \%$, respectively, of the betweengroup variability, while canonical $R^{2}$ values
(Table 2A) indicate that they account for $69.8 \%$ and $63.5 \%$, respectively, of the total relationship between groups and predictors. During stepwise entry of variables, all three predictors were entered with significance of $F<0.01$, in the order kurtosis, skew, $C V$. This shows that the model that best predicts group membership includes all three predictors, with kurtosis as the single best predictor.

The structure matrix (Table 2C), consisting of pooled within-group correlations between the discriminant functions and the predictor variables (skew, kurtosis, and CV), indicates which variables most reliably distinguish between groups along a particular discriminant function. It shows that the first discriminant function is most strongly correlated with kurtosis and the $C V$ (although there is also some correlation with skew). Figure 3 illustrates that this first function principally separates mammals + birds from the lepidosaur group and (to a slightly lesser extent) the testudine + crocodilian groups. Mammals + birds have more negative measures of kurtosis (Table 1), suggesting that their distributions of mandibular depth have relatively more truncated tails than distributions of testudine + crocodilian or lepidosaur mandibular depth (Fig. 1), while greater $C V$ values in testudines + crocodilians and lepidosaurs compared with mammals (Table 1) indicate that the diapsid mandibular depths are dispersed across a relatively greater size range than those of mammals + birds. The second discriminant function correlates most strongly with skew, and to a lesser extent with $C V$, and chiefly discriminates testudines + crocodilians from mammals + birds and lepidosaurs, with 
TABLE 2. Stepwise discriminant analysis with all species included.

\begin{tabular}{lccccc}
\hline \hline \multicolumn{4}{l}{ A. Eigenvalues and canonical correlations of predictor variables with groups for each function } \\
\hline $\begin{array}{l}\text { Discriminant } \\
\text { function }\end{array}$ & Eigenvalue & $\begin{array}{c}\text { \% of Between-group } \\
\text { variance }\end{array}$ & $\begin{array}{c}\text { Canonical } \\
\text { correlation }\end{array}$ & $\begin{array}{c}\text { Canonical } \\
R^{2}\end{array}$ & $\begin{array}{c}\text { 95\% Confidence } \\
\text { limits }\end{array}$ \\
\hline 1 & 2.305 & 57.0 & 0.835 & 0.6975 & $0.420-0.815$ \\
2 & 1.737 & 43.0 & 0.797 & 0.6346 & $0.328-0.772$ \\
\hline
\end{tabular}

B. Wilks's lambda and significance of functions

\begin{tabular}{lcccccc}
\hline $\begin{array}{l}\text { Test of } \\
\text { function(s) }\end{array}$ & $\begin{array}{c}\text { Wilks's } \\
\text { lambda }\end{array}$ & $\chi^{2}$ & $\begin{array}{c}\text { Degrees of } \\
\text { freedom }\end{array}$ & $p$-Value & $\begin{array}{c}\text { Partial } \eta^{2} \\
\text { (effect size) }\end{array}$ & $\begin{array}{c}\text { 95\% Confidence } \\
\text { limits }\end{array}$ \\
\hline 1 through 2 & 0.111 & 68.274 & 6 & 0.000000 & 0.5713 & $0.184-0.688$ \\
2 & 0.365 & 31.210 & 2 & 0.000000 & - & - \\
\hline
\end{tabular}

C. Structure matrix of correlations of predictor variables with the discriminant functions and their effect sizes

\begin{tabular}{|c|c|c|c|c|}
\hline & \multicolumn{2}{|c|}{$\begin{array}{l}\text { Correlations of predictor variables } \\
\text { with discriminant functions }\end{array}$} & \multicolumn{2}{|c|}{ Correlation effect size } \\
\hline & 1 & 2 & 1 & 2 \\
\hline $\begin{array}{l}\text { Transformed } \\
\text { kurtosis }\end{array}$ & -0.698 & 0.379 & 0.487 & 0.144 \\
\hline Transformed $C V$ & 0.707 & -0.332 & 0.501 & 0.111 \\
\hline $\begin{array}{l}\text { Transformed } \\
\text { skew }\end{array}$ & -0.556 & -0.461 & 0.309 & 0.212 \\
\hline
\end{tabular}

testudines + crocodilians showing greater values of skew and $C V$ than mammals + birds and lepidosaurs (Table 1). Skew is close to zero in testudine + crocodilian distributions, while skew of mammals and lepidosaurs distributions is negative, with that of lepidosaurs the most negative. This is because a few individual testudines and crocodilians with an extended pattern of adult growth grow to extreme size, increasing the proportion of data in the right tail of their mandibular depth distributions. This increase the $C V$ of their distributions and also results in more even left and right tails to their mandibular depth distributions than in determinately growing mammals + birds and lepidosaurs (Fig. 1). Lepidosaurs, in contrast, have the most unevenly distributed left and right tails, since they have determinate growth (truncated right tail) and slow juvenile growth (longer left tail), and hence the most negative skew.

To support the interpretation of structure matrix correlations and assess which predictors reliably separate each group from the other two groups after adjustment for the other predictor variables, we performed nine general linear model (GLM) runs in which means for each predictor for each group were contrasted with pooled means for the other two groups (Table 3). FDR corrections were applied to $p$-values for the nine contrasts. When contrasting mammals + birds with the pooled testudines + crocodilians and lepidosaurs and adjusting for all other predictors, we found mammals + birds to be significantly separated from the other groups by kurtosis and $C V$. Kurtosis and skew were found to significantly separate testudines + crocodilians from the other groups; and kurtosis, $C V$, and skew significantly separated lepidosaurs from the other groups. Therefore, all three predictor variables are important in discriminating between the three different growth classes. Mandibular depth distributions for mammals + birds are characterized by having a more negative kurtosis and lower $C V \mathrm{~s}$, reflecting both rapid juvenile growth and determinate, truncated adult growth (Fig. 1). Testudines + crocodilians have more positive values of kurtosis and values of skew that are close to zero, which is consistent with their mandibular depth distributions having two relatively long tails due to both slow juvenile growth and extended adult growth (Fig. 1). Finally, lepidosaur distributions are characterized by more 


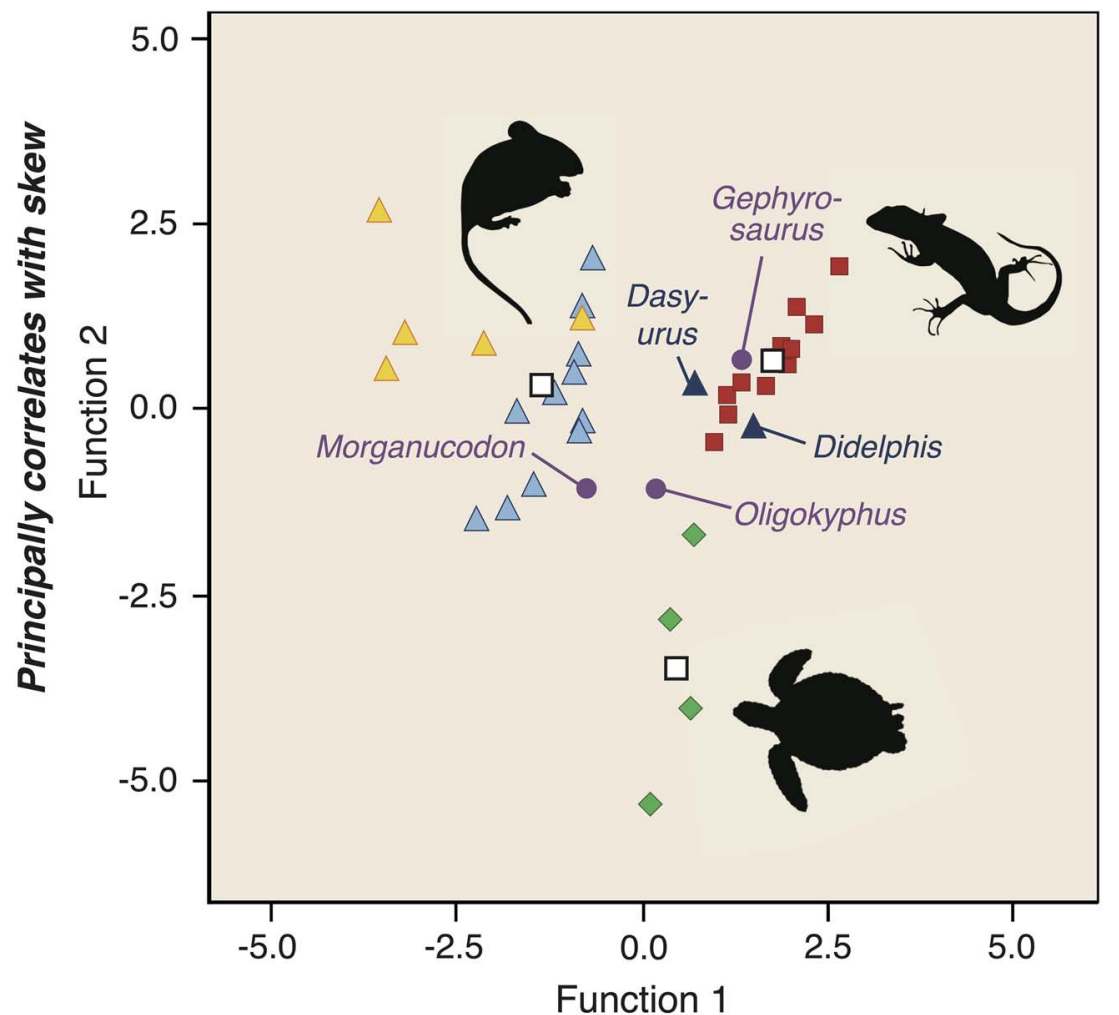

Growth Class

Mammal/Bird

$\triangle$ Placental

$\Delta$ Marsupial

$\triangle$ Bird

Lepidosaur

Testudine/

Crocodilian

Unknown

Group Centroid

\section{Principally correlates with CV and kurtosis}

FIGURE 3. Canonical discriminant function plot. Discriminant function analysis separated three growth classes (mammal + bird, lepidosaur, and testudine + crocodilian) on the basis of three predictor variables (skew, kurtosis, and $\mathrm{CV}$ ) that relate to the shape of size distributions of mandibular depth for each growth-class member. The first function principally separates amniotes with rapid juvenile growth (mammals + birds) from those with slow juvenile growth (testudines + crocodilians and lepidosaurs) and correlates most strongly with kurtosis and CV. The second function principally separates amniotes with extended growth (testudines + crocodilians) from those with determinate, truncated growth (mammals + birds and lepidosaurs) and correlates most strongly with skew. Classification functions derived from this analysis were used to predict growth-class membership for three fossil species of unknown growth class (Morganucodon, Oligokyphus, and Gephyrosaurus). The marsupials Didelphis and Dasyurus are positioned close to the lepidosaur growth class.

negative values of skew and $\mathrm{CVs}$ and kurtosis intermediate between mammals + birds and testudines + crocodilians, which is consistent with their determinate, truncated adult growth and slow juvenile growth.

\section{Classification of Species into Growth Categories}

Classification equations allow a species to be assigned to a particular group and were derived for each growth class in the discriminant function analysis. In these equations, predictor variable values for each subject are first multiplied by classification function coefficients (Tabachnick and Fidell 2007) and then summed and added to a constant to find classification scores. Classification scores can then be compared for each species across groups to assess group membership. Here, these equations were modified to take account of the differences in group size by using growth-class sample proportions as prior probabilities when assigning species to their growth classes. Posterior probabilities, or the conditional probability of growth-class membership under this model given the values of predictor variables, were calculated for all species. Of all original nonfossil species from which classification functions were derived, $100 \%$ were correctly classified, in comparison with the $41.5 \%$ expected by chance alone. 
TABLE 3. General linear model (GLM) contrasts of the mean of each predictor variable for each growth class against the pooled means for the other two growth classes. $p$-Values adjusted for multiple comparisons by FDR correction.

\begin{tabular}{|c|c|c|c|c|}
\hline \multirow[b]{2}{*}{ Contrast } & & \multicolumn{3}{|c|}{ Predictor (adjusted for all others) } \\
\hline & & Transformed kurtosis & Transformed $C V$ & Transformed skew \\
\hline \multirow[t]{3}{*}{ Mammals + birds vs. others } & $F_{(1,30)}$ & 7.47 & 5.01 & 0.47 \\
\hline & $p$-Value (after FDR) & 0.015 & 0.042 & 0.533 \\
\hline & Effect size (partial $\eta^{2}$ ) & 0.199 & 0.143 & 0.016 \\
\hline \multirow[t]{3}{*}{ Testudines + crocodilians vs. others } & $F_{(1,30)}$ & 25.86 & 0.40 & 26.73 \\
\hline & $p$-Value (after FDR) & 0.000 & 0.533 & 0.000 \\
\hline & Effect size (partial $\eta^{2}$ ) & 0.463 & 0.013 & 0.471 \\
\hline \multirow[t]{3}{*}{ Lepidosaurs vs. others } & $F_{(1,30)}$ & 7.92 & 10.68 & 44.82 \\
\hline & $p$-Value (after FDR) & 0.015 & 0.007 & 0.000 \\
\hline & Effect size (partial $\left.\eta^{2}\right)$ & 0.209 & 0.263 & 0.599 \\
\hline
\end{tabular}

TABLE 4. Posterior probabilities of group membership for fossil species and marsupial species in different discriminant function analyses. M/B, mammals + birds; T/C, testudines + crocodilians; L, lepidosaurs.

\begin{tabular}{|c|c|c|c|c|c|c|c|c|c|c|c|c|c|c|c|}
\hline & \multicolumn{15}{|c|}{ Posterior probability of group membership } \\
\hline & \multicolumn{3}{|c|}{ All taxa } & \multicolumn{3}{|c|}{$\begin{array}{l}\text { Marsupials } \\
\text { excluded }\end{array}$} & \multicolumn{3}{|c|}{$\begin{array}{l}\text { Didelphis only } \\
\text { excluded }\end{array}$} & \multicolumn{3}{|c|}{$\begin{array}{c}\text { All taxa } \\
\text { (size corrected) }\end{array}$} & \multicolumn{3}{|c|}{$\begin{array}{l}\text { Marsupials excluded } \\
\text { (size corrected) }\end{array}$} \\
\hline & $\mathrm{M} / \mathrm{B}$ & $\mathrm{T} / \mathrm{C}$ & $\mathrm{L}$ & $\mathrm{M} / \mathrm{B}$ & $\mathrm{T} / \mathrm{C}$ & $\mathrm{L}$ & $\mathrm{M} / \mathrm{B}$ & $\mathrm{T} / \mathrm{C}$ & $\mathrm{L}$ & $\mathrm{M} / \mathrm{B}$ & $\mathrm{T} / \mathrm{C}$ & $\mathrm{L}$ & $\mathrm{M} / \mathrm{B}$ & $\mathrm{T} / \mathrm{C}$ & $\mathrm{L}$ \\
\hline Morganucodon & 1.000 & 0.000 & 0.000 & 1.000 & 0.000 & 0.000 & 1.000 & 0.000 & 0.000 & 1.000 & 0.000 & 0.000 & 1.000 & 0.000 & 0.000 \\
\hline Oligokyphus & 0.815 & 0.012 & 0.173 & 0.690 & 0.015 & 0.294 & 0.783 & 0.005 & 0.212 & 0.664 & 0.324 & 0.012 & 0.516 & 0.460 & 0.024 \\
\hline Gephyrosaurus & 0.261 & 0.016 & 0.723 & 0.036 & 0.030 & 0.934 & 0.121 & 0.033 & 0.847 & 0.053 & 0.000 & 0.947 & 0.007 & 0.000 & 0.993 \\
\hline Dasyurus & 0.900 & 0.100 & 0.000 & - & - & - & 0.871 & 0.128 & 0.000 & 0.705 & 0.285 & 0.010 & - & - & - \\
\hline Didelphis & 0.550 & 0.004 & 0.446 & - & - & - & - & - & - & 0.022 & 0.000 & 0.978 & - & - & - \\
\hline
\end{tabular}

All extant species were classified to their correct groups with posterior probabilities greater than 0.85 , with the exception of Didelphis, which was classified correctly as a mammal but with very low probability $(p p=0.550$; Table 4). All five species of birds were classified correctly in the mammal + bird growth class with posterior probabilities in excess of 0.999. In the canonical discriminant plot (Fig. 3), birds appear to form a small cluster somewhat overlapping with placental mammals and distant from both lepidosaurs and testudines + crocodilians.

Of the three fossil species with unknown growth patterns, Morganucodon was classified in the mammal group ( $p p=1.000$; Table 4$)$ and occupies a position in the canonical discriminant function plot (Fig. 3) that is close to but not within the cluster of placental mammal species. Oligokyphus occupies an intermediate position between all three groups in the plot of canonical discriminant functions (Fig. 3). It has the greatest posterior probability of membership in the mammal group ( $p p=0.815$; Table 4$)$, although this is lower than mammal-group probabilities exhibited by Morganucodon and all placental species. Gephyrosaurus is classified with highest posterior probability $(p p=0.732$; Table 4) as a lepidosaur and occupies a position in the discriminant function plot (Fig. 3) very close to that group.

A cross-validation run was performed to assess the stability of the classification procedure. Classification functions, from which group memberships of unknown fossil species are estimated, were derived from approximately $75 \%$ of the extant species selected at random, while the remainder were withheld as cross-validation data. For the species used to derive classification functions (training data), correct classification rate was $96.2 \%$, while for the withheld cross-validation species, correct classification was $100 \%$, indicating that the classification procedure has high consistency. Didelphis, which was classified as a lepidosaur rather than as mammal, was the only incorrectly classified taxon among the training data. 


\section{Additional Discriminant Function Analyses}

The entire discriminant function analysis was repeated, excluding Canis, Dasyurus, Fringilla, and Columba, to test whether problems relating to their sample sizes biased results. Their exclusion alters the results of the analysis very little (Supplementary Material S4) and does not change the conclusions of this study. Repeating the analysis using only those measurements from greyhounds as Canis data also results in minimal changes to the results, with Canis classified as a mammal with $p p=1.000$ in both cases, whether using all dogs or only greyhounds.

The analysis was also repeated excluding the marsupials Didelphis and Dasyurus. These taxa are located closer to the lepidosaurs than placental mammals in the canonical discriminant function plot (Fig. 3), suggesting that marsupials may form a growth class distinct from placental mammals by having slower juvenile growth. They were therefore excluded to test whether this alters the positions of Morganucodon and Oligokyphus in discriminant function plots. Again, exclusion does not significantly alter overall results of the analysis (Supplementary Material S3.1). Morganucodon and Oligokyphus occupy similar positions in the discriminant function plot in comparison with the analysis with marsupials included (Fig. 3). However, the classification of Oligokyphus changes; the posterior probability of mammal + bird group membership drops from $p p=$ 0.815 with marsupials included to $p p=0.6690$ when marsupials are excluded (Table 4$)$. This underscores the differences in growth patterns between Oligokyphus and Morganucodon; the latter taxon remains classified with the placental mammal group at $p p=1.000$ (Table 4) when marsupials are excluded.

\section{The Effects of Body-Size and Life History Data}

Three size and life history variables were included in another stepwise discriminant analysis to assess whether any discriminant function correlates strongly with these variables (in addition to skew, kurtosis, or $C V$ ). If so, this would confound the effects of growth, as it would be difficult to distinguish whether consistent differences in skew, kurtosis, and
$C V$, which discriminate between growth classes, are due to growth or to consistent differences in the life history variables.

Due to the small sample size of the testudine + crocodilian group and the fact that the number of predictor variables cannot exceed the size of the smallest group in a discriminant analysis (Tabachnick and Fidell 2007), it was necessary to collapse the lepidosaur group with testudines + crocodilians into one diapsid group (which differs in growth strategy from mammals + birds in having slow, rather than rapid, juvenile growth). Species for which life history data were missing were excluded.

Only one function is extracted by this analysis, since only two groups are discriminated. This function is highly significant (Wilks's lambda $=0.462, \chi^{2}{ }_{(6)}=19.7, p<0.001$; see Supplementary Material S6.1), indicating that it reliably discriminates between mammals and diapsids, and its canonical $R^{2}$ value shows that it explains $53.8 \%$ of the total relationship between groups and predictors. During stepwise entry of variables, only $C V$ was entered into the analysis with significance of $F<0.05$. This shows that the model that best predicts mammal + bird versus nonavian diapsid group membership only requires $C V$ and is not improved by the addition of other variables. This function separates mammals + birds from diapsids on the basis of the more restricted distributions of the former and reflects rapid juvenile growth and determinate, truncated adult growth in mammals, and slower juvenile growth in diapsids. This is not surprising, since this function corresponds with the first discriminant function of the main analysis (Fig. 3, x-axis), which separates mammals from lepidosaurs and testudines + crocodilians (i.e., diapsids) chiefly on the basis of $C V$ and kurtosis. Since none of the size or life history variables were included in the stepwise analysis, this suggests that they do not reliably discriminate between groups.

When testudines + crocodilians are collapsed with the mammal + bird group and contrasted against lepidosaurs, conclusions differ little from those described above for diapsids versus mammals. One function was extracted, and stepwise entry of variables resulted in three variables being included in 
the analysis with significance of $F<0.05$. These were entered in the order skew, $C V$, size. The structure matrix of correlations between the discriminant function and the predictor variables (Supplementary Material S6.2.3) shows that of the three entered variables, the function correlates most strongly with skew. The correlation of the size variable with the function is very weak $(-0.140)$ and shares less than $2 \%$ of variance with the function. This is below the minimum level of correlation (0.32; sharing $10 \%$ of variance) recommended by Comrey and Lee (1992) for meaningful interpretation. Again, this suggests that neither size nor any life history variable reliably discriminates between the groups. It is therefore unlikely that consistent differences in life history variables are causing the consistent differences in the combinations of skew, kurtosis, and $C V$. Rather, these differences in skew, kurtosis, and $C V$ are due to differences in growth pattern between groups.

These analyses test for the effects of body size and life history on the extant taxa with known growth patterns. While data regarding life history variables are not available for the fossil taxa, their body-size data can be included. To assess the effect of body size on the classification of the fossil taxa while also retaining three growth classes (rather than collapsing two together), we performed linear regression of the three predictor variables against body size. The residuals from these regressions were then used as size-corrected skew, kurtosis, and $C V$ variables in a further discriminant function analysis. The results of this analysis differ very little from the main analysis, with only minor changes in interpretation of correlations of the discriminant functions (e.g., a slightly higher correlation of kurtosis with the second discriminant function; Supplementary Material S7), which do not alter any conclusions drawn from the main analysis.

\section{Discussion}

Discriminant function analysis on skew, kurtosis, and $C V$ of mandibular depth distributions showed that these measures reliably discriminate between at least three patterns of growth: mammal + bird (rapid juvenile growth, determinate, truncated adult growth), lepidosaur (slow juvenile growth, determinate, truncated adult growth), and testudine + crocodilian (slow juvenile growth, extended adult growth). Marsupials appear to have a pattern of growth distinct from placental mammals and may comprise a fourth pattern, while some species of birds exhibit juvenile growth that is even more rapid than that of most placental mammals. Growth in Morganucodon is very similar to that of extant small placental mammals, with both determinate, truncated adult growth and rapid juvenile growth. Oligokyphus is intermediate between placental mammals and diapsids; in comparison with Morganucodon and placental mammals Oligokyphus shows somewhat slower juvenile growth and somewhat more extended adult growth.

\section{Using Distribution Shape to Discriminate between Growth Patterns}

The two discriminant functions extracted from the main discriminant analysis were highly significant, indicating that they both reliably discriminated between members of different growth classes, with relatively high effect sizes (canonical correlations; Table 2A) (Tabachnick and Fidell 2007).

The first discriminant function (Fig. 3) primarily separates amniotes with rapid juvenile growth (mammals + birds) from those with slower juvenile growth on the basis of more negatively kurtotic distributions, with lower $C V$ in the mammal + bird group. The second discriminant function primarily separates members of the testudine + crocodilian growth class, with extended adult growth, from the other two groups, which have determinate, truncated adult growth. This function correlates most strongly with the skew and $C V$ of individual species' data distributions. Together with GLM analysis, this shows that the combinations of predictors for discriminating between different groups reflect the expected differences between these groups given their respective growth strategies.

Broad within-group phylogenetic diversity, permitted by the inclusion of species with 
convergently acquired characters, reduces the confounding effects of phylogeny on functional associations in multivariate approaches (Chen and Wilson 2015). Thus, while it is possible that phylogenetic signal in both predictor variables and growth classes may underlie some of our observed pattern (Harvey and Pagel 1991), the clustering of species with convergently acquired growth strategies suggests that functional effects of growth explain these patterns better than phylogenetic signal alone. Birds, which convergently acquired rapid juvenile growth and determinate, truncated adult growth, cluster within the same growth class as mammals with very high posterior probabilities (all species > 0.999), somewhat overlapping with placentals (Fig. 3), and very distant from lepidosaurs and testudines + crocodilians (which are all more closely related to birds than are mammals; Fig. 1). Marsupials cluster more closely to distantly related lepidosaurs than to placental mammals, possibly owing to their slower juvenile growth (see "Growth Patterns of Didelphis" section).

If skew, kurtosis, and $C V$ of mandibular distributions were influenced primarily by inherited characteristics (other than growth pattern), there would be no particular reason for combinations of characteristic skew, kurtosis, and $C V$ patterns produced by such a phylogenetic signal to coincide so closely with those expected from growth. This is particularly evident in those cases in which species do not cluster with other members of their clade but to a more distantly related group with which they share particular growth characteristics; in these species, not only do their predictor variable values differ from those of their closer relatives, but the predictor variables differ in exactly the way one would expect given their differing growth patterns. Not only do marsupials not cluster with placental mammals, but differences in skew, kurtosis, and $C V$ imply much slower juvenile growth in marsupials than in placentals, which is consistent with known growth differences between placentals and marsupials (TyndaleBiscoe 2001). Similarly, birds resemble placentals rather than other diapsids, and several species also show more negative kurtosis and lower CVs than placentals (Fig. 3; Supplementary Material S1), consistent with even more rapid juvenile growth in many bird species (Case 1978).

This analysis therefore derives discriminant functions that reliably distinguish between growth classes on the basis of predictor variables relating to the shape of mandibular depth distributions, and although a phylogenetic signal may be present, the functional effect of growth is clearly the most important driver separating classes.

\section{The Effects of Life History and Body Size}

If certain attributes of size or life history strategy were clumped in one particular growth class, it would be difficult to disentangle whether the differences in distribution shape for this group were due to its different growth strategy or influenced by size or life history strategy. However, the inclusion of size and life history variables in further discriminant function analyses showed that these variables do not discriminate reliably between diapsids and mammals or between lepidosaurs and a collapsed mammal + bird + testudine + crocodilian group (Supplementary Material S6). This suggests that size and life history variables are relatively evenly spread through the three different groups and are therefore unlikely to be causing the consistent differences in patterns of skew, kurtosis, and $C V$ that distinguish between the growth classes.

Furthermore, discriminant function analysis carried out on the three predictor variables after correction for size made very little difference to results in comparison with the main analysis (Supplementary Material S7.5). Morganucodon and Oligokyphus are both still classified with highest posterior probability in the mammal group (Morganucodon: $p p=1.000$; Oligokyphus: $p p=0.664$; Table 4), although the posterior probability of mammal group membership of Oligokyphus is somewhat reduced in comparison with the main analysis $(p p=0.815$; Table 4), and Oligokyphus has a slightly closer relationship with both the lepidosaur and testudine + crocodilian groups in the discriminant function plot. However, this alters none of the conclusions of this study and suggests that 
size differences have not greatly affected this analysis. Exclusion of the largest mammals (Canis and Dasyurus) did not alter the conclusions either (Supplementary Material S4), nor did use of only greyhound data rather than data from all dogs. Nonetheless, given the more prolonged growth period in larger mammals such as elephants and ruminants (Lee and Werning 2008; Köhler et al. 2012), far larger in size than the fossils of relevance to this study, future investigations could profitably focus on the effects of including a greater number of large-bodied taxa.

\section{Predicting Group Membership-Growth Patterns of Didelphis}

Classification functions from the main analysis (not including size and life history variables) predict group membership well, with $100 \%$ of all original grouped cases being correctly classified in comparison with the $41.5 \%$ expected by chance alone. A crossvalidation run indicated that the classification procedure had high consistency. While all species were classified correctly, one mammal species, Didelphis, was classified with much lower posterior probability than any other $(p p=0.550$ in comparison with $p p>0.90$ for all placental mammals; Table 4).

One hypothesis to account for this is that, in common with other marsupials, Didelphis exhibits growth patterns that differ from those of placental mammals, a hypothesis supported by the close position of our other sampled marsupial, Dasyurus, to the lepidosaur group in the discriminant function plot (Fig. 3). Epiphyseal growth plate closure is consistently delayed or lacking in many marsupials, and growth may continue throughout life (Geiger et al. 2014). Marsupials also have a very derived reproductive strategy, with a prolonged period of lactation resulting in slower and more prolonged juvenile growth (TyndaleBiscoe 2001), which may explain why the growth patterns of marsupials such as Didelphis and Dasyurus more closely resemble the lepidosaur growth pattern than that of placental mammals. Unlike Didelphis, Dasyurus was classified as a mammal with relatively high probability ( $p p=0.900$; Table 4$)$. However, this is lower than the posterior probability of any placental mammal, which for all species exceeds 0.999. In addition, when Didelphis alone was excluded from the analysis, Dasyurus had a somewhat reduced posterior probability of mammal + bird growth-class membership ( $p p=0.871$ in comparison with $p p>0.99$ for all placental mammals; Table 4). This suggests that inclusion of Didelphis within the placental mammal + bird growth class may have artificially raised the probability of inclusion of Dasyurus in this growth class and that marsupials represent a growth class distinct from placental mammals. However, robust testing of this hypothesis would require a greater sample size of marsupial taxa.

\section{Growth Patterns in Morganucodon and Oligokyphus}

Morganucodon and Oligokyphus were assigned to growth classes using classification functions derived from the extant and extinct species of known growth patterns. Morganucodon exhibits placental mammal-like growth on the basis of skew, kurtosis, and $C V$, with a posterior probability of mammal + bird class membership of 1.000. Oligokyphus was classified with the mammal + bird growth class with a relatively high posterior probability $(p p=0.815)$.

The question arises as to whether a statistical model derived from data distributions of extant species can be used to predict group membership of extinct species whose data distributions may be subject to different biases, most notably preservation bias. The truncation of the left tail of Morganucodon's data distribution may be due to placental-like rapid juvenile growth, or it may be due to poor preservation of smaller juvenile individuals with less ossified skeletons. To avoid conflating the effects of growth and preservation bias, we included Gephyrosaurus in our study. Gephyrosaurus is an extinct rhynchocephalian that likely had lepidosaur growth patterns (Chinsamy and Hurum 2006). It is of the same age and size and from the same Glamorgan fissure-fill deposits as Morganucodon (Evans 1980; Evans and Kermack 1994). Oligokyphus, although from a slightly more recent locality, is from fissure-fill deposits similar to those at Glamorgan; both deposits 
were likely formed by predator-accumulated skeletal material being washed into an underground water system (Kühne 1956; Evans and Kermack 1994).

As expected, Gephyrosaurus is classified with extant lepidosaurs (slow juvenile growth, determinate, truncated adult growth) with high posterior probability $(p p=0.732)$. Its distribution is strongly negatively skewed with a long left tail, suggesting that the absence of such a tail in the Morganucodon distribution is not due to preservation bias but to differences in growth between Morganucodon and Gephyrosaurus. Thus, we conclude that Morganucodon has rapid juvenile growth in contrast with slower juvenile growth in Gephyrosaurus.

The classification of Morganucodon in the mammal + bird growth class is based on its placental mammal-like values of skew, kurtosis, and $C V$. While its kurtosis is less negative than that of placental mammals, it is still more negative than that of any testudine + crocodilian or lepidosaur (Supplementary Material S1). This suggests that Morganucodon is likely to have had an almost typically placental growth pattern of both rapid juvenile growth and determinate, truncated adult growth.

However, growth patterns in Morganucodon are not identical with those observed in the sample of modern placentals. In the canonical discriminant function plot (Fig. 3), Morganucodon is situated on the edge of the placental mammal group; of all the placental mammals and birds, it is among the closest to either of the diapsid groups. Less rapid juvenile growth may be the more important underlying difference separating Morganucodon from extant placentals. In the canonical discriminant function plot (Fig. 3), Morganucodon is on the most extreme edge of the placental mammal group in the first discriminant function direction. In comparison it is well within the range of extant placentals in the second discriminant function. The second function separates chelonians + crocodilians from the other groups chiefly because their more extended growth patterns cause longer right tails in the distributions, and so skew is closer to zero than in the other groups. The fact that Morganucodon does not differ so greatly from most other mammals in the second discriminant function indicates that differences in growth in Morganucodon are not principally due to it having a slightly more extended growth pattern than most extant placentals. Rather, it suggests that Morganucodon has slightly less rapid juvenile growth, leading to data dispersed over a greater range and with less negative kurtosis than in most placental mammals (indeed, Morganucodon has less negative kurtosis than any placental mammal), and hence a more extreme position of Morganucodon in the first discriminant function. Nevertheless, Morganucodon also has relatively low values in the second discriminant function, suggesting that both a slightly less rapid juvenile growth combined with a slightly more extended adult growth pattern position Morganucodon at the extreme edge of the extant placental mammal group.

Oligokyphus occupies a position that is intermediate between all three major growth classes in the canonical discriminant function plot (Fig. 3), regardless of the inclusion or exclusion of marsupials. It is positioned closer to the testudine + crocodilian and lepidosaur growth classes than is Morganucodon. This suggests that growth in Oligokyphus may have approached the placental mammalian condition, while still differing from growth patterns seen in most extant mammals and Morganucodon, for example, by having less rapid juvenile growth or adult growth that did not terminate so abruptly as in extant mammals.

Oligokyphus differs from extant placental mammals to a greater extent in the first discriminant function than in the second. This may suggest that slower juvenile growth patterns exerted a strong influence in separating it from Morganucodon and extant mammals. However, the position of Oligokyphus in the discriminant function plot is also very close to the testudine + crocodilian group (Fig. 3). Indeed, when size is corrected for, the position of Oligokyphus is extremely close to that of the green turtle, Chelonia, and Oligokyphus has a much higher posterior probability of membership in the testudines + crocodilian group $(p p=0.324)$ than the lepidosaur group $(p p=$ 0.012 ). This difference is even more marked (testudine + crocodilian membership: $p p=$ 0.460; lepidosaur membership: $p p=0.024$ ) when the two marsupial species are removed 
from the analysis, since they artificially enlarge the discriminant function space occupied by the mammal + bird group. This suggests that Oligokyphus may have had somewhat less rapid juvenile growth than extant placental mammals but differed more prominently from placentals and Morganucodon in having a more extended growth period. This is consistent with evidence from bone histology; tritylodontids had sustained, uninterrupted growth that slowed later in ontogeny (Botha-Brink et al. 2012), but fully grown Oligokyphus specimens with peripheral rest lines have yet to be sampled, so it is possible that growth was more extended in Oligokyphus than Morganucodon. Further study incorporating more lepidosaurs and testudines + crocodilians of a variety of sizes would help to further interpret how growth in Oligokyphus differs from Morganucodon.

As previously noted, we assume that the sampled Oligokyphus specimens derive from a single species (Kühne 1956); any conclusions about growth in this species must be reconsidered if our sample does in fact comprise two species.

\section{Growth Patterns and the Evolution of Mammalian Biology}

In combination with other evidence from skull size ranges (Luo et al. 2001), ratios of juvenile to adult specimens (Parrington 1971; Kermack et al. 1973, 1981; Gow 1985), and bone histology (Chinsamy and Hurum 2006), the results of this study support determinate, truncated adult growth and rapid juvenile growth patterns in Morganucodon, as suggested for M. oehleri by Luo et al. (2004). Oligokyphus differed from Morganucodon in growth, possibly in having slightly less rapid juvenile growth but more likely in having a somewhat more extended period of growth. This is indicated by its closer affiliation with the testudines + crocodilian group than the lepidosaur group. Supporting evidence for such growth patterns in Oligokyphus is provided by bone histology, which suggests that juvenile growth is very rapid in Oligokyphus, with reproductive maturity reached within a year, while growth after this may well have been extended relative to Morganudocon.
This suggests that the evolution of rapid growth occurred in synapsids more basal than Oligokyphus and that truncated adult growth evolved from morganucodontans crownward, subsequent to the evolution of key mammaliaform traits such as the squamosal-dentary jaw articulation. Thus, the origin of a determinate, truncated pattern of adult growth may have followed the evolution of rapid juvenile growth. The origin of determinate truncated adult growth may then have permitted reduction of tooth replacement to diphyodont patterns. These conclusions are consistent with existing hypotheses that link the evolution of determinate growth and of rapid juvenile growth with the origin of diphyodonty (Luo et al. 2004).

Most nonmammaliaform cynodonts have multiple, alternate dental replacements across the entire dentition (Crompton 1963; Osborn and Crompton 1973; Kielan-Jaworowska et al. 2004; Abdala et al. 2013). Replacement patterns, especially of the postcanines, are somewhat reduced in more crownward taxa such as Probainognathus (Crompton and Jenkins 1979), Brasilodon (Martinelli and Bonaparte 2011), tritylodontids, and Sinoconodon (Zhang et al. 1998; Luo et al. 2004; Abdala et al. 2013). Such a reduction in tooth replacement may have been permitted by more rapid rates of juvenile growth. Morganucodon is the most basal known synapsid to have a diphyodont replacement pattern typical of extant mammals (Luo et al. 2004). The placental-like truncated growth patterns of Morganucodon would have restricted the time at which the jaw was at an intermediate size, hence reducing the requirement for multiple replacements of teeth (Zhang et al. 1998) and permitting a diphyodont pattern of tooth replacement.

Applying the techniques used in this study to other mammaliaform and cynodont taxa could further test this hypothesis of the dependence of diphyodonty on the evolution of both rapid juvenile growth and determinate, truncated growth. This hypothesis would predict that relatively placental-like patterns of growth should occur in cynodonts with very reduced dental replacement. Hence, Sinoconodon, which has reduced postcanine replacement (somewhat similar to tritylodontids), 
should have growth patterns at least resembling those of Oligokyphus, if not placental mammals. Luo et al. (2001) inferred growth patterns were less mammal-like in Sinoconodon than in Morganucodon, but further work is required to assess growth in Sinoconodon relative to more basal cynodonts. It should be noted that a hypothesis of placental-like growth enabling diphyodonty to evolve does not necessarily exclude the possibility of rapid and truncated growth rates evolving more basally than the origin of diphyodonty. Given evidence from bone histology, it is possible that this has occurred in several therapsid taxa, for example, therocephalians (Huttenlocker and Botha-Brink 2014), Thrinaxodon (Botha and Chinsamy 2005), and Galesaurus (Butler 2010). Inclusion of more basal taxa in a similar analysis, permitting direct comparison with those examined here, could be useful in understanding how growth evolved more basally in the synapsid lineage.

\section{Summary}

Our results permit a more nuanced interpretation of growth across the cynodont-tomammaliaform transition than a dichotomy between determinate versus extended growth. Like other mammalian features, growth patterns known today among placental mammals evolved gradually (Kemp 2007). Growth in Morganucodon closely resembled extant placental mammals, while in Oligokyphus, growth was intermediate with slightly less rapid juvenile growth and more extended adult growth than in Morganucodon. Given that true diphyodonty was present in Morganucodon but not more stemward cynodonts (e.g., Oligokyphus, Sinoconodon), this is consistent with the hypothesis that placental-like growth enabled diphyodont replacement.

Rapid juvenile growth combined with more truncated (determinate) adult growth in basal mammaliaforms enabled reduction of dental replacement and may also comprise indirect evidence for the evolution of lactation (Zhang et al. 1998; Luo et al. 2004). A reduction in tooth replacement, together with truncated, determinate growth, may have permitted the evolution of more precise molar occlusion (Crompton and Jenkins 1973; Pond 1977; Crompton 1995) in more crownward mammaliaforms, as the relative positions of teeth could remain constant in adult animals. These dental characteristics are in turn integrated with a suite of other potentially correlated characteristics, such as mammalian masticatory function (Crompton 1995) and endothermy (Kemp 2005), which have been of vital importance in the subsequent evolution of mammals.

\section{Acknowledgments}

The authors would like to thank two anonymous reviewers for their thoughtful comments, which improved both the methodology and interpretation of results. We are indebted to Ian Corfe for helpful advice regarding Oligokyphus that expanded the scope of this study and to Michel Laurin and David Marjanović who provided helpful comments on the manuscript. Thanks go to John Aston and Brian McCabe for statistical advice. Gephyrosaurus specimens were provided by Susan Evans (University College London), while Alan Resetar (Field Museum of Natural History, Chicago), Sylvia Humphries (Hancock Museum, Newcastle), Patrick Campbell (Natural History Museum, London), Sandra Chapman (Natural History Museum, London), Roberto Portela Miguez (Natural History Museum London), Małgosia Nowak-Kemp (Oxford University Museum of Natural History), Emma-Louise Nicholls (University College London, Grant Museum of Zoology), and Matthew Lowe (University Museum of Zoology, Cambridge) facilitated access to specimens at museum collections. R.N.O.'s work is funded by the Cambridge Home and EU Scholarship Scheme.

\section{Literature Cited}

Abdala, F., S. C. Jasinoski, and V. Fernandez. 2013. Ontogeny of the Early Triassic cynodont Thrinaxodon liorhinus (Therapsida): dental morphology and replacement. Journal of Vertebrate Paleontology 33:1408-1431.

Adolph, S. C., and W. P. Porter. 1996. Growth, seasonality, and lizard life histories: age and size at maturity. Oikos 77:267-278.

Andrews, R. M. 1982. Patterns of growth in reptiles. Pp. 273-320 in C. Gans, and F. H. Pough, eds. Biology of the Reptilia, Vol. 13. Academic, New York. 
Asher, R. J., and T. Lehmann. 2008. Dental eruption in afrotherian mammals. BMC Biology 6:14.

Asher, R. J., and G. Olbricht. 2009. Dental ontogeny in Macroscelides proboscideus (Afrotheria) and Erinaceus europaeus (Lipotyphla). Journal of Mammalian Evolution 16:99-115.

Balazs, G. H. 1980. Synopsis of biological data on the green turtle in the Hawaiian islands. NOAA Technical Memorandum NMFS, NOAA-SWFC-7. U.S. Department of Commerce.

Barr, W. A., and R. S. Scott. 2014. Phylogenetic comparative methods complement discriminant function analysis in ecomorphology. American Journal of Physical Anthropology 153:663-674.

Benjamini, Y., and Y. Hochberg. 1995. Controlling the false discovery rate: a practical and powerful approach to multiple testing. Journal of the Royal Statistical Society B 57:289-300.

Bjorndal, K. A., J. Parsons, W. Mustin, and A. B. Bolten. 2013. Threshold to maturity in a long-lived reptile: interactions of age, size, and growth. Marine Biology 160:607-616.

Botha, J., and A. Chinsamy. 2000. Growth patterns deduced from the histology of the cynodonts Diademodon and Cynognathus. Journal of Vertebrate Paleontology 20:705-711.

—. 2005. Growth patterns of Thrinaxodon liorhinus, a nonmammalian cynodont from the Lower Triassic of South Africa. Palaeontology 48:385-394.

Botha-Brink, J., F. Abdala, and A. Chinsamy-Turan. 2012. The radiation and osteohistology of nonmammaliaform cynodonts. Pp. 222-246 in A. Chinsamy-Turan, ed. Forerunners of mammals: radiation, histology, biology. Indiana University Press, Bloomington.

Butler, E. 2010. The post-cranial skeleton of the Early Triassic nonmammalian cynodont Galesaurus planiceps: implications for biology and lifestyle. Master's dissertation, University of the Free State, Bloemfontein, South Africa.

Butler, P. M. 1995. Ontogenetic aspects of dental evolution. International Journal of Developmental Biology 39:25-34.

Carr, A., and D. Goodman. 1970. Ecologic implications of size and growth in Chelonia. Copeia 4:783-786.

Case, T. J. 1978. On the evolution and adaptive significance of postnatal growth rates in the terrestrial vertebrates. Quarterly Review of Biology 53:243-282.

Castanet, J., and M. Báez. 1991. Adaptation and evolution in Gallotia lizards from the Canary Islands: age, growth, maturity and longevity. Amphibia-Reptilia 12:81-102.

Castanet, J., D. G. Newman, and H. Saint Girons. 1988. Skeletochronological data on the growth, age and population structure of the tuatara, Sphenodon punctatus, on the Stephens and Lady Alice islands, New Zealand. Herpetologica 44:25-37.

Charnov, E. L., T. F. Turner, and K. O. Winemiller. 2001. Reproductive constraints and the evolution of life histories with indeterminate growth. Proceedings of the National Academy of Sciences USA 98:9460-9464.

Chen, M., and G. P. Wilson. 2015. A multivariate approach to infer locomotor modes in Mesozoic mammals. Paleobiology 41: 280-312.

Chiari, Y., V. Cahais, N. Galtier, and F. Delsuc. 2012. Phylogenomic analyses support the position of turtles as the sister group of birds and crocodiles (Archosauria). BMC Biology 10:65.

Chinsamy, A., and F. Abdala. 2008. Palaeobiological implications of the bone microstructure of South American traversodontids (Therapsida: Cynodontia). South African Journal of Science 104:225-230.

Chinsamy, A., and J. H. Hurum. 2006. Bone microstructure and growth patterns of early mammals. Acta Palaeontologica Polonica 51:325-338.

Chinsamy, A., S. A. Hanrahan, R. M. Neto, and M. Seely. 1995. Skeletochronological assessment of age in Angolosaurus skoogi, a cordylid lizard living in an aseasonal environment. Journal of Herpetology 29:457-460.
Ciancio, M. R., M. C. Castro, F. C. Galliari, A. A. Carlini, and R. J. Asher. 2012. Evolutionary implications of dental eruption in Dasypus (Xenarthra). Journal of Mammalian Evolution 19:1-8.

Clemens, W. A. 1979. A problem in morganucodontid taxonomy. Zoological Journal of the Linnean Society 66:1-14.

Comrey, A. L., and H. B. Lee. 1992. A first course in factor analysis, 2nd ed. Erlbaum, Hillsdale, N.J.

Congdon, J. D., R. D. Nagle, O. M. Kinney, R. C. van Loben Sels, T. Quinter, and D. W. Tinkle. 2003. Testing hypotheses of aging in long-lived painted turtles (Chrysemys picta). Experimental Gerontology 38:765-772.

Congdon, J. D., J. Whitfield Gibbons, R. J. Brooks, N. Rollinson, and R. N. Tsaliagos. 2013. Indeterminate growth in long-lived freshwater turtles as a component of individual fitness. Evolutionary Ecology 27:445-459.

Cothran, E. G., M. J. Aivaliotis, and J. L. Vandeberg. 1985. The effects of diet on growth and reproduction in grey short-tailed opossums, Monodelphis domestica. Journal of Experimental Zoology 236:103-114.

Cott, H. B. 1961. Scientific results of an inquiry into the ecology and economic status of the Nile crocodile (Crocodylus niloticus) in Uganda and northern Rhodesia. Transactions of the Zoological Society of London 29:211-256.

Crawford, N. G., J. F. Parham, A. B. Sellas, B. C. Faircloth, T. C. Glenn, T. J. Papenfuss, J. B. Henderson, M. H. Hansen, and W. B. Simison. 2015. A phylogenomic analysis of turtles. Molecular Phylogenetics and Evolution 83:250-257.

Crompton, A. W. 1963. Tooth replacement in the cynodont Thrinaxodon liorhinus Seeley. Annals of the South African Museum 46:479-521.

- 1995. Masticatory function in nonmammalian cynodonts and early mammals. Pp. 55-75 in J. J. Thomason, ed. Functional morphology in vertebrate paleontology. Cambridge University Press, Cambridge.

Crompton, A. W., and F. A. Jenkins. 1973. Mammals from reptiles: a review of mammalian origins. Annual Review of Earth and Planetary Sciences 1:131-155.

_. 1979. Origin of mammals. Pp. 59-73 in J. Lillegraven Z. Kielan-Jaworowska, and W. Clemens, eds. Mesozoic mammals: the first two thirds of mammalian history. University of California Press, Berkeley.

Crompton, A. W., and Z.-X. Luo. 1993. Relationships of the Liassic mammals Sinoconodon, Morganucodon, and Dinnetherium. Pp. 30-44 in F. S. Szalay, M. J. Novacek, and M. C. McKenna, eds. Mammal phylogeny: mesozoic differentiation, multituberculates, monotremes, early therians, and marsupials. Springer, New York.

Crompton, A. W., and P. Parker. 1978. Evolution of the mammalian masticatory apparatus: the fossil record shows how mammals evolved both complex chewing mechanisms and an effective middle ear, two structures that distinguish them from reptiles. American Scientist 66:192-201.

Crompton, A. W., C. B. Wood, and D. N. Stern. 1994. Differential wear of enamel: a mechanism for maintaining sharp cutting edges. Advances in Comparative and Environmental Physiology 18:321-346.

Curran-Everett, D. 2000. Multiple comparisons: philosophies and illustrations. American Journal of Physiology: Regulatory, Integrative and Comparative Physiology 279:1-8.

Dawbin, W. H. 1982. The tuatara Sphenodon punctatus: aspects of life history, growth and longevity. In D. G. Newman, ed. New Zealand herpetology. New Zealand Wildlife Service, Department of Internal Affairs, Occasional Publications 2: 237-250.

de Buffrénil, V., I. Ineich, and W. Böhme. 2004. Comparative data on epiphyseal development in the family Varanidae. Journal of Herpetology 37:328-335. 
de Magalhaes, J. P., and J. Costa. 2009. A database of vertebrate longevity records and their relation to other life-history traits. Journal of Evolutionary Biology 22:1770-1774.

de Ricqlès, A. 1969. Recherches paléohistologiques sur les os longs des Tétrapodes. II, Quelques observations sur la structure des longs des Thériodontes. Annales de Paléontologie (Vertébrés) 55:1-52.

—. 1976. On bone histology of fossil and living reptiles, with comments on its functional and evolutionary significance. Pp. 123-150 in A. A. Bellairs, and C. B. Cox, eds. Morphology and biology of reptiles (Linnean Society Symposium Series No. 3). Academic, London.

Dice, L. R., and R. M. Bradley. 1942. Growth in the deer-mouse, Peromyscus maniculatus. Journal of Mammalogy 23:416-427.

Dunham, A. E., and J. W. Gibbons. 1990. Growth of the slider turtle. Pp. 135-145 in J. W. Gibbons, ed. Life history and ecology of the slider turtle. Smithsonian Institution Press, Washington, D.C.

Edmund, A. G. 1960. Tooth replacement phenomena in the lower vertebrates. Contributions of Royal Ontario Museum, Life Science Division 52:1-190.

Eisen, E. J. 1976. Results of growth curve analyses in mice and rats. Journal of Animal Science 42:1008-1023.

Erickson, G. M. 2005. Assessing dinosaur growth patterns: a microscopic revolution. Trends in Ecology and Evolution 20:677-684.

Erickson, G. M., K. Curry Rogers, and S. A. Yerby. 2001. Dinosaurian growth patterns and rapid avian growth rates. Nature 412:429-433.

Evans, S. E. 1980. The skull of a new eosuchian reptile from the Lower Jurassic of South Wales. Zoological Journal of the Linnean Society 70:203-264.

Evans, S. E., and M. E. H. Jones. 2010. The origin, early history and diversification of lepidosauromorph reptiles. In S. Bandyopadhyay, ed. New aspects of Mesozoic biodiversity. Lecture Notes in Earth Sciences 132:27-44. Springer, Berlin.

Evans, S. E., and K. A. Kermack. 1994. Assemblages of small tetrapods from the Early Jurassic of Britain. Pp. 271-283 in N. C. Fraser, and H.-D. Sues, eds. In the shadow of the dinosaurs. Cambridge University Press, Cambridge.

Ewer, R. F. 1963. Reptilian tooth replacement. News Bulletin of the Zoological Society of South Africa 4:4-9.

Fernandez, S. 1998. Age, growth and calving season of bottlenose dolphins, Tursiops truncatus, off coastal Texas. Fishery Bulletin 96:357-365.

Frazer, N. B., and R. C. Ladner. 1986. A growth curve for green sea turtles, Chelonia mydas, in the U.S. Virgin Islands, 1913-14. Copeia 3:798-802.

Geiger, M., A. M. Forasiepi, D. Koyabu, and M. R. Sánchez-Villagra. 2014. Heterochrony and post-natal growth in mammals-an examination of growth plates in limbs. Journal of Evolutionary Biology 27:98-115.

Godfrey, L. R., K. E. Samonds, P.C. Wright, and S. J. King. 2005. Schultz's unruly rule: dental developmental sequences and schedules in small-bodied, folivorous lemurs. Folia Primatologica 76:77-99.

Gow, C. E. 1985. Apomorphies of the Mammalia. South African Journal of Science 81:558-560.

Grine, F. E., and E. S. Vrba. 1980. Prismatic enamel: a preadaptation for mammalian diphyodonty? South African Journal of Science 76:139-141.

Haines, R. W. 1969. Epiphyses and sesamoids. Pp. 81-115 in C. Gans, A. d'A. Bellairs, and T. S. Parsons, eds. Biology of the Reptilia, Vol. 1A. Morphology. Academic, London.

Harvey, P. H., and M. D. Pagel. 1991. The comparative method in evolutionary biology. Oxford University Press, Oxford.

Helmink, S. K., R. D. Shanks, and E. A. Leighton. 2000. Breed and sex differences in growth curves for two breeds of dog guides. Journal of Animal Science 78:27-32.
Hopson, J. A. 1971. Postcanine replacement in the gomphodont cynodont Diademodon. Pp. 1-21 in D. M. Kermack, and K. A. Kermack, eds. Early mammals. Academic, London.

- 1973. Endothermy, small size and the origin of mammalian reproduction. American Naturalist 107:446-452.

Hurum, J. H., and A. Chinsamy-Turan. 2012. The radiation, bone histology, and biology of early mammals. Pp. 248-270 in A. Chinsamy-Turan, ed. Forerunners of mammals: radiation, histology, biology. Indiana University Press, Bloomington.

Huttenlocker, A. K., and J. Botha-Brink. 2014. Bone microstructure and the evolution of growth patterns in Permo-Triassic therocephalians (Amniota, Therapsida) of South Africa. PeerJ 2:e325.

Jackson, C. M., and L. G. Lowrey. 1912. On the relative growth of the component parts (head, trunk and extremities) and systems (skin, skeleton, musculature and viscera) of the albino rat. Anatomical Record 6:449-474.

Jenkins, F. A., and C. R. Schaff. 1988. The Early Cretaceous mammal Gobiconodon (Mammalia, Triconodonta) from the Cloverly Formation in Montana. Journal of Vertebrate Paleontology 8:1-24.

Kemp, T. S. 2005. The origin and evolution of mammals. Oxford University Press, Oxford.

- 2007. The concept of correlated progression as the basis of a model for the evolutionary origin of major new taxa. Proceedings of the Royal Society of London B 274:1667-1673.

Kermack, K. A., and D. M. Kermack. 1984. Evolution of mammalian characters. Croom Helm, London.

Kermack, K. A., F. Mussett, and H. W. Rigney. 1973. The lower jaw of Morganucodon. Zoological Journal of the Linnean Society 53:87-175.

- 1981. The skull of Morganucodon. Zoological Journal of the Linnean Society 71:1-158.

Kielan-Jaworowska, Z., and D. Dashzeveg. 1998. Early Cretaceous amphilestid ('triconodont') mammals from Mongolia. Acta Palaeontologica Polonica 43:413-438.

Kielan-Jaworowska, Z., R. L. Cifelli, and Z.-X. Luo. 2004. Mammals from the age of dinosaurs: origins, evolution and structure. Columbia University Press, New York.

Köhler, M., N. Marín-Moratalla, X. Jordana, and R. Aanes. 2012. Seasonal bone growth and physiology in endotherms shed light on dinosaur physiology. Nature 487:358-361.

Kolarov, T., K. Ljubisavljević, L. Polović, G. Džukić, and M. L. Kalezić. 2010. The body size, age structure and growth pattern of the endemic Balkan Mosor rock lizard (Dinarolacerta mosorensis, Kolombatović, 1886). Acta Zoologica Academiae Scientiarum Hungaricae 56:55-71.

Krogman, W. M. 1931. Growth changes in the skull and face of the gorilla. American Journal of Anatomy 47:89-115.

Kühne, W. G. 1956. The Liassic therapsid Oligokyphus. Trustees of the British Museum, London.

Lee, A. H., and S. Werning. 2008. Sexual maturity in growing dinosaurs does not fit reptilian growth models. Proceedings of the National Academy of Sciences USA 105:582-587.

Lee, A. H., A. K. Huttenlocker, K. Padian, and H. N. Woodward. 2013. Analysis of growth rates. Pp. 217-251 in K. Padian, and E.-T. Lamm, eds. Bone histology of fossil tetrapods: advancing methods, analysis and interpretation. University of California Press, Berkeley.

Lovich, J. E., C. H. Ernst, and J. F. McBreen. 1990. Growth, maturity, and sexual dimorphism in the wood turtle, Clemmys insculpta. Canadian Journal Zoology 68:672-677.

Luo, Z.-X. 1994. Sister-group relationships of mammals and transformations of diagnostic mammalian characters. Pp. 98-128 in N. C. Fraser, and H.-D. Sues, eds. In the shadow of the dinosaurs. Cambridge University Press, Cambridge.

Luo, Z.-X., A. W. Crompton, and A.-L. Sun. 2001. A new mammal from the Early Jurassic and evolution of mammalian characteristics. Science 292:1535-1540. 
Luo, Z.-X., Z. Kielan-Jaworowska, and R. L. Cifelli. 2002. In quest for a phylogeny of Mesozoic mammals. Acta Palaeontologica Polonica 47:1-78.

- 2004. Evolution of dental replacement in mammals. Bulletin of the Carnegie Museum of Natural History 36:159-175.

Maisano, J. A. 2002. Terminal fusions of skeletal elements as indicators of maturity in squamates. Journal of Vertebrate Paleontology 22:268-275.

Martin, T., and M. Nowotny. 2000. The docodont Haldanodon from the Guimarota mine. Pp. 91-96 in T. Martin, and B. Krebs, eds. Guimarota-a Jurassic ecosystem. Verlag Dr. Friedrich Pfeil, Munich.

Martinelli, A. G., and J. F. Bonaparte. 2011. Postcanine replacement in Brasilodon and Brasilitherium (Cynodontia, Probainognathia) and its bearing in cynodont evolution. Pp. 179-186 in J. Calvo, J. Porfiri, B. Gonzales Riga, and D. Dos Santos, eds. Paleontología y Dinosaurios desde América Latina Editora de la Universidad de Cuyo. Mendoza, Argentina.

Moss, M. L., and M. J. Baer. 1956. Differential growth of the rat skull. Growth 20:107-120.

Mills, J. R. E. 1971. The dentition of Morganucodon. Pp. 29-63 in D. M. Kermack, and K. A. Kermack, eds. Early mammals. Academic, London.

Münkemüller, T., S. Lavergne, B. Bzeznik, S. Dray, T. Jombart, K. Schiffers, and W. Thuiller. 2012. How to measure and test phylogenetic signal. Methods in Ecology and Evolution 3:743-756.

Nesterenko, V., and S. Ohdachi. 2001. Postnatal growth and development in Sorex unguiculatus. Mammal Study 26:145-148.

Nowotny, M., T. Martin, and M. S. Fischer. 2001. Dental anatomy and tooth replacement of Haldanodon exspectatus (Docodonta, Mammalia) from the Upper Jurassic of Portugal. Journal of Morphology 248:268.

Osborn, J. W. 1971. The ontogeny of tooth succession in Lacerta vivipara, Jacquine (1787). Proceedings of the Royal Society of London B 179:261-289.

- 1974. On the control of tooth replacement in reptiles and its relationship to growth. Journal of Theoretical Biology 46:509-527.

Osborn, J. W., and A. W. Crompton. 1973. The evolution of mammalian from reptilian dentitions. Breviora 399:1-18.

Padian, K., A. J. de Ricqlès, and J. R. Horner. 2001. Dinosaurian growth rates and bird origins. Nature 412:405-408.

Parrington, F. R. 1971. On the Upper Triassic mammals. Philosophical Transactions of the Royal Society of London B 261:231-272. - 1973. The dentitions of the earliest mammals. Zoological Journal of the Linnean Society 52:85-95.

- 1978. A further account of the Triassic mammals. Philosophical Transactions of the Royal Society of London B 282: 177-204.

Pond, C. M. 1977. The significance of lactation in the evolution of mammals. Evolution 31:177-199.

Porter, K. R. 1972. Herpetology. Saunders, Philadelphia.

Ray, S., S. Bandyopadhyay, and D. Bhawal. 2009. Growth patterns as deduced from bone microstructure of some selected neotherapsids with special emphasis on dicynodonts: phylogenetic implications. Palaeoworld 18:53-66.

Ray, S., J. Botha, and A. Chinsamy. 2004. Bone histology and growth patterns of some nonmammalian therapsids. Journal of Vertebrate Paleontology 24:634-648.

R Core Team. 2012. R: a language and environment for statistical computing. R Foundation for Statistical Computing, Vienna, Austria. http:/ / www.R-project.org.

Robinson, P. L. 1957. The Mesozoic fissures of the Bristol Channel area and their vertebrate faunas. Zoological Journal of the Linnean Society 43:260-282.
Rootes, W. L., R. H. Chabreck, V. L. Wright, B. W. Brown, and T. J. Hess. 1991. Growth rates of American alligators in estuarine and palustrine wetlands in Louisiana. Estuaries 14:489-494.

Rowe, T. B. 1998. Definition, diagnosis, and origin of Mammalia. Journal of Vertebrate Paleontology 8:241-264.

Säilä, L. K. 2005. A new species of the sphenodontian reptile Clevosaurus, from the Lower Jurassic of South Wales. Palaeontology 48:817-831.

Sander, P. M., and N. Klein. 2005. Developmental plasticity in the life history of a prosauropod dinosaur. Science 310:1800-1802.

Scheyer, T. M., N. Klein, and M. Sander. 2010. Developmental palaeontology of Reptilia as revealed by histological studies. Seminars in Cell and Developmental Biology 21:462-470.

Schrader, A. M., S. M. Ferreira, M. E. McElveen, P.C. Lee, C. J. Moss, and R. J. van Aarde. 2006. Growth and age determination of African savanna elephants. Journal of Zoology 270:40-48.

Sebens, K. P. 1987. The ecology of indeterminate growth in animals. Annual Review of Ecology and Systematics 18:71-407.

Seminoff, J. A., A. Resendiz, W. J. Nichols, and T. T. Jones. 2002. Growth rates of wild green turtles (Chelonia mydas) at a temperate foraging area in the Gulf of California, México. Copeia 3:610-617.

Shine, R., and E. L. Charnov. 1992. Patterns of survival, growth, and maturation in snakes and lizards. American Naturalist 39: 1257-1269.

Shine, R., and J. B. Iverson. 1995. Patterns of survival, growth and maturation in turtles. Oikos 72:343-348.

Sokal, R. R., and F. J. Rohlf. 2012. Biometry, 4th ed. Freeman, New York.

Tabachnick, B. G., and L. S. Fidell. 2007. Using Multivariate Statistics, 5th ed. Pearson Education, Boston.

Tucker, A. D., C. J. Limpus, K. R. McDonald, and H. I. McCallum. 2006. Growth dynamics of freshwater crocodiles (Crocodylus johnstoni) in the Lynd River, Queensland. Australian Journal of Zoology 54:409-415.

Tyndale-Biscoe, C. H. 2001. Australasian marsupials-to cherish and to hold. Reproduction, Fertility and Development 13: $477-485$.

van Devender, R. W. 1978. Growth ecology of a tropical lizard, Basiliscus basiliscus. Ecology 59:1031-1038.

Westergaard, B., and M. W. J. Ferguson. 1986. Development of the dentition in Alligator mississippiensis. Early embryonic development in the lower jaw. Journal of Zoology 210:575-597.

- 1987. Development of the dentition in Alligator mississippiensis. Later development in the lower jaws of embryos, hatchlings and young juveniles. Journal of Zoology 212:199-222.

Wilkinson, P. M., and W. E. Rhodes. 1997. Growth rates of American alligators in coastal South Carolina. Journal of Wildlife Management 61:397-402.

Woodward, H. N., J. R. Horner, and J. O. Farlow. 2011. Osteohistological evidence for determinate growth in the American alligator. Journal of Herpetology 45:339-342.

Zhang, F.-K., A. W. Crompton, Z.-X. Luo, and C. R. Schaff. 1998. Pattern of dental replacement of Sinoconodon and its implications for evolution of mammals. Vertebrata PalAsiatica 36:197-217.

Zug, G. R., A. H. Wynn, and C. Ruckdeschel. 1986. Age determination of loggerhead sea turtles, Caretta caretta, by incremental growth marks in the skeleton. Smithsonian Contributions to Zoology 427:1-34.

Zúñiga-Vega, J. J., R. I. Rojas-González, J. A. Lemos-Espinal, and M. E. Pérez-Trejo. 2005. Growth ecology of the lizard Xenosaurus grandis in Veracruz, México. Journal of Herpetology 39:433-443. 